\title{
Persée
}

http://www.persee.fr

\section{La fuerza de los Cuatro Vientos. Los manuscritos 20 y 21 del "fonds mexicain"}

\author{
Maarten Jansen \\ Journal de la société des américanistes, Année 1998, Volume 84, Numéro 2 \\ p. $125-161$
}

\section{Voir l'article en ligne}

La force des quatre vents : les manuscrits 20 et 21 du fonds mexicain de la BNF Les manuscrits 20 (original) et 21 (copie) du fonds mexicain de la BNF combinent des toponymes de la tradition des codex historiques mixtèques avec des personnages du groupe Borgia à caractère divinatoire et rituel. Les toponymes représentent les quatre directions et le centre et les lieux primordiaux du monde mixtèque. Les personnages sont les Mères qui périrent en accouchant et les Pères qui moururent à la guerre : ils apparaissent comme les patrons des quatre directions et du centre et comme ceux des cinq segments du tonalpohualli. Le document pictographique peut être lu comme la prière d'un prêtre-chamane («mère-père ") qui invoque les pouvoirs de purification, de guérison et d'affermissement des ancêtres ; comme tel, ce manuscrit peut être vu comme un élément d'un rituel mixtèque de limpia et peut être comparé avec les peintures sur sable et les chants navajo. La guerre est l'élément qui fait le lien entre les scènes et il est possible que le manuscrit-prière ait fait partie des préparatifs pour une bataille réelle. Métaphoriquement, cependant, la guerre peut apparaître comme un équivalent de la mise au monde d'un être vivant, de la lutte quotidienne pour la survie et des combats contre les difficultés, les dangers et les traumatismes de l'existence.

\section{Avertissement}

L'éditeur du site «PERSEE » - le Ministère de la jeunesse, de l'éducation nationale et de la recherche, Direction de l'enseignement supérieur, Sous-direction des bibliothèques et de la documentation - détient la propriété intellectuelle et les droits d'exploitation. A ce titre il est titulaire des droits d'auteur et du droit sui generis du producteur de bases de données sur ce site conformément à la loi n`98-536 du 1er juillet 1998 relative aux bases de données.

Les oeuvres reproduites sur le site «PERSEE » sont protégées par les dispositions générales du Code de la propriété intellectuelle.

Droits et devoirs des utilisateurs

Pour un usage strictement privé, la simple reproduction du contenu de ce site est libre.

Pour un usage scientifique ou pédagogique, à des fins de recherches, d'enseignement ou de communication excluant toute exploitation commerciale, la reproduction et la communication au public du contenu de ce site sont autorisées, sous réserve que celles-ci servent d'illustration, ne soient pas substantielles et ne soient pas expressément limitées (plans ou photographies). La mention Le Ministère de la jeunesse, de l'éducation nationale et de la recherche, Direction de l'enseignement supérieur, Sous-direction des bibliothèques et de la documentation sur chaque reproduction tirée du site est obligatoire ainsi que le nom de la revue et- lorsqu'ils sont indiqués - le nom de l'auteur et la référence du document reproduit.

Toute autre reproduction ou communication au public, intégrale ou substantielle du contenu de ce site, par quelque procédé que ce soit, de l'éditeur original de l'oeuvre, de l'auteur et de ses ayants droit.

La reproduction et l'exploitation des photographies et des plans, y compris à des fins commerciales, doivent être autorisés par l'éditeur du site, Le Ministère de la jeunesse, de l'éducation nationale et de la recherche, Direction de l'enseignement supérieur, Sous-direction des bibliothèques et de la documentation (voir http://www.sup.adc.education.fr/bib/ ). La source et les crédits devront toujours être mentionnés. 


\title{
LA FUERZA DE LOS CUATRO VIENTOS LOS MANUSCRITOS 20 Y 21 DEL FONDS MEXICAIN ${ }^{1}$
}

\author{
Maarten JANSEN *
}

Los manuscritos 20 (original) y 21 (copia) del fonds mexicain de la Bibliothèque nationale de France combinan topónimos de la tradición de los códices mixtecos con personajes del grupo Borgia de carácter divinatorio y ritual. Los topónimos representan las cuatro direcciones y el centro así como los lugares primordiales del mundo mixteco. Los personajes, por su parte, son las madres que murieron en el parto y los padres que cayeron en la guerra; aparecen como patrones de los cuatro rumbos y del centro así como de los cinco segmentos del tonalpohualli. El documento puede ser leído como la oración de un sacerdote-shamán ("madre-padre ") que invoca el poder de purificación, curación y fortalezimiento de aquellos ancestros ; el manuscrito puede ser considerado como parte de un ritual mixteco de limpia y comparado con las pinturas en arena y los cantos navajos. La guerra es el elemento que relaciona entre sí las distintas escenas, y puede ser que el manuscrito/oración haya formado parte de los preparativos concretos para una batalla histórica. En un plan metafórico, sin embargo, la guerra puede ser un equivalente del parto, de la lucha cotidiana para sobrevivir y de los combates contra las dificultades, los peligros y los traumas de la vida.

Palabras Claves: Bibliothèque nationale de France, fonds mexicain, Mixteca, cosmología, geografia, calendario, ritual de purificación, guerra, parto, oración shamánica.

\section{La force des quatre vents : les manuscrits 20 et 21 du fonds mexicain de la BNF}

Les manuscrits 20 (original) et 21 (copie) du fonds mexicain de la BNF combinent des toponymes de la tradition des codex historiques mixtèques avec des personnages du groupe Borgia à caractère divinatoire et rituel. Les toponymes représentent les quatre directions et le centre et les lieux primordiaux du monde mixtèque. Les personnages sont les Mères qui périrent en accouchant et les Pères qui moururent à la guerre : ils apparaissent comme les patrons des quatre directions et du centre et comme ceux des cinq segments du tonalpohualli. Le document pictographique peut être lu comme la prière d'un prêtre-chamane (" mère-père ") qui invoque les pouvoirs de purification, de guérison et d'affermissement des ancêtres ; comme tel, ce manuscrit peut être vu comme un élément d'un rituel mixtèque de limpia et peut être comparé avec les peintures sur sable et les chants navajo. La guerre est l'élément qui fait le lien entre les scènes et il est possible que le manuscrit-prière ait fait partie des préparatifs pour une bataille

* Archeologisch Centrum, Rijksuniversiteit Leiden, P.O.B. 9515, 2300 RA Leiden, Holland.

Mél : <M.Jansen@arch. LeidenUniv.nl>

Journal de la Société des Américanistes 1998, 84-2 : p. 125 à 161. Copyright C) Société des Américanistes. 
réelle. Métaphoriquement, cependant, la guerre peut apparaître comme un équivalent de la mise au monde d'un être vivant, de la lutte quotidienne pour la survie et des combats contre les difficultés, les dangers et les traumatismes de l'existence.

Mots Clés : Bibliothèque nationale de France, fonds mexicain, Mixteca, cosmologie, géographie, calendrier rituel, rite de purification, guerre, accouchement, prière chamanique.

The strength of the four winds: The fonds mexicain manuscripts 20 and 21

Manuscripts 20 (original) and 21 (copy) of the fonds mexicain combine toponyms from the Mixtec historical codices with personages from the divinatory-ritual Borgia group. The toponyms represent the four directions and the centre, the primordial places of the Mixtec world. The personages are the Mothers who died in childbirth and the Fathers who died in war. They are represented as the patrons of the four directions and the centre and as the patrons of the five segments of the tonalpoualli. The painting can be read as the prayer of a shaman-priest ( " mother-father »), who calls upon the purifying, healing and strengthening powers of those ancestors. As such, the manuscript may be visualized as part of a Mixtec limpia ritual and may be compared with the Navajo sandpaintings and chants. War is the connecting element of the scenes, so an actual preparation for battle may have motivated this prayer. As a metaphor, however, war can also stand for giving birth, for the daily struggle to survive, and for surmounting the difficulties, dangers and traumas of life in general.

KEY WoRDS : Bibliothèque nationale de France, fonds mexicain, Mixteca, cosmology, geography, ritual calendar, purification rite, war, childbirth, chamanic prayer.

Great spirit, I chant for your help

once again.

The strength of the four winds braced my mind.

My song set me free for I have

dared to dream

before of life-giving

freedom.

Bobby Gene García

El manuscrito que simplemente se designa como el número 20 de la colección Aubin-Goupil o fonds mexicain de la Bibliothèque nationale de France, y que aquí abreviamos mex. 20, consta de una sola página de piel de venado de $91 \times 51 \mathrm{~cm}$ (Figura X a colores). No es propiamente un códice (libro), ni un lienzo. Como bien es sabido, perteneció al Museo Indiano del infortunado caballero italiano Lorenzo Boturini Benaduci (1702-1755). No sabemos cómo llegó a sus manos. En su Idea de una Nueva Historia General de la América Septentrional (1746), Boturini lo colocó en la misma categoría que el manuscrito hoy conocido como el Tonalamatl Aubin, y, aunque lo llama un "mapa », lo interpretó como un documento calendárico-ritual. Observó que tenía « un círculo en el medio de cuentas coloradas, que forman los números de 4 Triadecatéridas, acompañadas de una cabeza de conejo ». Efectiva- 
mente contamos alrededor de la escena central 51 puntos que juntos con el signo del día [5] Conejo forman la cantidad de 52. Luego Boturini dijo que " se ven en los 4 ángulos de este mapa diferentes figuras de ídolos muy feos, que eran como guardas y custodios del ciclo, a los cuales, así en el ingreso de él como en su salida, se hacían grandes fiestas » (Boturini 1974, p. 139). Las "triadecatéridas » son las unidades de trece días o años, que hoy en día llamamos "trecenas ". En este caso Boturini se refería a años : en otro inventario (citado por Lehmann 1966, p. 147) esta " rueda de cuentas » es llamado " el siglo indiano de 52 años ».

Hoy en día las figuras dentro del círculo central se han borrado en su mayor parte, pero se pueden reconstruir a base de las dos copias tempranas que existen : una en el mismo fonds mexicain (manuscrito $\mathrm{n}^{\circ} 21$ : véase Figura XI a colores) y otra en el Museo Nacional de Antropología, México. Ambas copias son atribuidas a Antonio de León y Gama y generalmente se supone que estas copias se basan en lo que se distinguía aún en el siglo XVIII ${ }^{2}$. Nos referimos aquí al mex. 20, tomando en cuenta que se debe reconstruir la escena central a base del fonds mexicain 21 y de la otra copia.

La historia de cómo la colección de Boturini fue requisada y de cómo una parte llegó a París es bien conocida. Boban publicó una reproducción (sin color) del mex. 20 y de su copia (mex. 21) en el Atlas de su gran catálogo (1891) y explicó el contenido como un " culto al sol " (culte rendu au soleil), pensando en la ideología mexica del «Quinto Sol ». Según Boban, los personajes centrales están mirando hacia arriba para hacer observaciones astronómicas y las otras escenas contienen referencias a las destrucciones de los «soles » o creaciones anteriores. Fue una proposición basada más en la imaginación que en argumentos sólidos.

Fue poco después, en el tiempo en que el gran maestro Eduard Seler escribió sus fundamentales comentarios sobre los códices religiosos conocidos en conjunto como " el Grupo Borgia ", que su alumno Walter Lehmann, en un clásico estudio monográfico (1905), publicó un análisis detallado y riguroso del mex. 20. Lehmann pensó que se trataba de un manuscrito zapoteco, demostró que los paisajes en las esquinas y el centro se referían a los puntos cardinales, e identificó a las cinco parejas como seres divinos con la iconografía de Macuilxochitl y Tlazolteotl, respectivamente, es decir como cinco Uitznaua ( Sureños », patronos de la creatividad y del libertinaje) y cinco Ciuateteo (mujeres muertas en el parto y después deificadas). En cuanto a los paisajes direccionales, observó, hay un paralelismo notable con el Codex Vindobonensis, y en cuanto a las parejas con el Codex Borgia y el Codex Vaticanus B.

Desde luego, el análisis de Lehmann se conecta con los estudios sobre el Codex Borgia y el Vaticanus B que hizo su maestro, Eduard Seler (1887, 1902, 1904-1909). Éste llamó a las figuras masculinas Auiateteo, " dioses del placer », y las relacionó con Nanauatzin, el buboso o sifilítico que se convirtió en el sol. Después de un análisis exhaustivo, concluyó :

"Los dioses marcados con el número " cinco " y los que llevan " cinco " en su nombre, o sea Macuilxochitl y sus compañeros, no representan, como Xochipilli, la alegría en sí, el goce, la música, la danza, la abundancia de alimentos etc., sino la excesiva entrega al placer, las inclinaciones pecaminosas, así como a los castigados por sus excesos, muy especialmente a aquellos que son castigados con enfermedades venéreas. » (Seler 1963, II, pp. 76-77).

A las Ciuateteo, las parturientas muertas que moran en el occidente, Seler las interpretó de una manera similar, de acuerdo con las nociones victorianas de su 
tiempo y con el paradigma astralista (Astraldeutung) que estaba de moda y dominaba sus estudios :

" Se sobrentiende que la verdadera razón por la cual se asociaba a esas diosas con el Oeste es porque este punto cardinal era la región de la oscuridad, de la tarde, del Sol que se pone. Pero debido a una asociación de ideas muy natural, se les confundía con la Luna que sale en el Cielo occidental. Y así se explica que a ellas se traspusiera no sólo todo el complejo de representaciones derivado del antagonismo entre la Luna y el Sol, sino también todo lo relacionado con el misterioso y alarmante vínculo que une a la Luna con las mujeres y la menstruación, es decir, con el tremendo poder, extraño y enigmático, de lo femenino. Las cihuateteo eran también los demonios que seducían a los hombres a la impudicia, al adulterio, al pecado. » (Seler 1963, II, p. 73).

En su gran obra sobre los códices religiosos mexicanos, Tlacuilolli (1961), Karl Anton Nowotny presentó una visión global y sistemática de su contenido, reemplazando el paradigma astralista de Seler por un enfoque sobre el carácter mántico de los símbolos ${ }^{3}$. Discutió brevemente el mex. 20, distinguiendo claramente tres elementos : la estructura calendárica, las figuras y los paisajes. En la crónica Histoyre du Mechique aparece el término Tonalleque, "los dueños del tonalli (" día " y " alma ") " como nombre de la deidad asociada con los días que tienen el número 5. De ahí que Nowotny designó a las figuras masculinas como Tonalleque, mientras que para las mujeres usó Ciuapipiltin, "Nobles Señoras", sinónimo de Ciuateteo. Confirmando que los paisajes representan los puntos cardinales, Nowotny (1959) notó que éstos no sólo aparecen en los códices Vindobonensis y Porfirio Díaz (que hoy llamamos Codex de Tututepetongo), sino también en el Rollo Selden y en el Lienzo Antonio de León (que hoy llamamos Lienzo de Tlapiltepec).

En un artículo que acompaña la traducción española del estudio de Lehmann, Alfonso Caso (1966) elaboró este argumento. Este autor ya había demostrado en su clásico estudio sobre el Mapa de Teozacualco (1949) que el Vindobonensis y todo un grupo de códices relacionados provienen de la Mixteca Alta. Observando que los signos toponímicos en cuestión aparecen en esos códices mixtecos, en conjunto y por separado, Caso concluyó :

«Podemos decir, en consecuencia, que la pintura $n^{\circ} 20$, se refiere a lugares que existían realmente en la Mixteca y que se consideraban como situados en los puntos cardinales y el centro. " (Caso 1966, p. 189).

Además Caso presentó un resumen aclarador de la estructura calendárica y enfatizó el carácter guerrero de las parejas, a las que, siguiendo a Nowotny, llamó Tonalleque y Ciuapipiltin. Desde esta perspectiva Caso de repente revivió un aspecto de la interpretación de Boban :

" Me parece que la pintura no representa simplemente los cuatro puntos cardinales y el centro, sino que se refiere a una guerra, propiamente a la " guerra sagrada ", la Xochiyaoyotl que tenía por objeto rendir culto al sol. » (Caso 1966, p. 187).

Otro aspecto de la vieja idea de Boban ha sido recuperado en la publicación reciente de Brotherston (1995, pp. 149-150), que, tomando en cuenta el desciframiento de los topónimos como signos de los puntos cardinales, compara de nuevo la compo- 
sición del mex. 20 con la famosa Piedra del Sol o Calendario azteca y encuentra en las escenas referencias a las destrucciones de los soles o épocas anteriores.

De esta breve historia de las principales interpretaciones resalta el carácter especial y fascinante del mex. 20 : por una parte participa, en el ámbito simbólico-religioso, de los códices mánticos-rituales (el « Grupo Borgia »), por otra, en el ámbito geográficohistórico, de los códices narrativos de la Mixteca.

En investigaciones más recientes se ha intentado interpretar los códices y monumentos mesoamericanos explícitamente desde el mundo indígena, y, por eso, se ha prestado cada vez más atención a la tradición viva (véanse por ejemplo Tedlock 1982, Jansen 1982, Loo 1987, Anders \& Jansen 1988, Freidel, Schele \& Parker 1993, López Austin 1994, Anders \& Jansen 1994, Doesburg \& Carrera González 1996). Teniendo este cambio paradigmático en mente, trataremos a nuestra vez de explorar las distintas capas de significación del mex. 20 y las relaciones que existen entre ellas. El primer paso debe ser localizar los topónimos y establecer su vínculo con la realidad geográfica (cf. Jansen 1982, pp. 228 sqq.).

\section{LOS LUGARES DE ESTABLECIMIENTO Y DE PODER}

En las cuatro esquinas y en el centro del mex. 20 hay cinco " paisajes » o conjuntos de signos toponímicos. El paralelo más claro es el apuntado por Lehmann : el Codex Vindobonensis, que, como ha demostrado Caso, es un manuscrito mixteco - pienso que proviene de Tilantongo. El contexto es el de la fundación de los señoríos en la Mixteca. En forma abreviada y con algunas variaciones este conjunto de signos aparece también en otros códices mixtecos. En el Bodley (de Tilantongo) se menciona en asociación con la muerte de los príncipes de lo que parece ser la "época anterior", los señores de Monte que se Abre/Insecto, sitio que he identificado como Monte Albán (Bodley, pp. 3-4).

En el Colombino-Becker (que viene de Tututepec en la Costa) estos signos se combinan con árboles y representan puntos ante los cuales el señor 8 Venado rinde culto cuando sube sucesivamente al trono de Tututepec y de Tilantongo (Colombino, pp. IV-V y p. XVII).

Referencias incidentales ocurren en el Nuttall (asociado con Teozacualco), el Selden (de Jaltepec) y el « Fragmento de Nochixtlan » (que, a pesar de su nombre, viene de la Mixteca Baja). El tema de los cuatro jeroglíficos es muy popular en los lienzos del Valle de Coixtlahuaca, donde lo vemos en el Lienzo de Tlapiltepec, el Lienzo de Tequixtepec I, el Fragmento Gómez de Orozco y el Rollo Selden, siempre en asociación con la escena de la fundación del señorío.

Al igual que mex. 20, el Codex de Tututepetongo (Porfirio Díaz) presenta el conjunto de los cuatro jeroglíficos toponímicos en un contexto mántico (Figura 1) - es un manuscrito pictográfico cuicateco, el único miembro del Grupo Borgia cuya procedencia conocemos con exactitud ${ }^{4}$.

Un dato esencial para identificar este conjunto de signos es el vocabulario mixteco de fray Francisco de Alvarado (1593). Los términos que él da para las cuatro direcciones coinciden perfectamente con estos signos y confirman la atribución de los investigadores arriba mencionados. 
FIG. 1. - Los veinte signos calendáricos distribuidos sobre las cuatro direcciones, Codex de Tututepetongo (Porfirio Diaz), p. 33.

El tema de estos cuatro o cinco signos de los puntos cardinales aparece en un área bastante bien definida : la parte norte de la Mixteca Alta, entre Tilantongo (Bodley, Vindobonensis), Tepozcolula (Alvarado), el Valle de Coixtlahuaca (Lienzos de Tlapiltepec y Tequixtepec) y Tututepetongo en la Cañada cuicateca (Porfirio Díaz).

El mex. 20 sitúa los signos de acuerdo con su distribución en el espacio.

1. - En la esquina derecha superior está el cielo : una banda azul con signos de estrellas y, en medio, el sol. Encima de esta banda está una hilera de cuchillos de pedernal, un motivo que encontramos con frecuencia en combinación con el ámbito 
celeste en los códices (por ejemplo, Becker, p. 4 ; Borgia, pp. 33-34). De las traducciones que Alvarado da para «levante, parte oriental » y "levante, viento oriental » deducimos que el término mixteco antiguo para oriente es : andevui, sa yocana ndicandii, sa yocana ñuhu, "Cielo, donde sale el sol, donde sale ñuhu (la luz o el Dios)".

En Vindobonensis (p. 13) vemos igualmente una banda celestial. Los otros códices también muestran un cielo, un sol, un templo del cielo, etc. El Colombino (pp. IV, XVII) da una alternativa : el árbol con un ñuhu (Dios) que surge del suelo ${ }^{5}$. Algo similar, un templo con plumas en un valle de jade, donde surge el $\tilde{n} u h u$, vemos en otra lista de estos signos direccionales en Vindobonensis, p. 45.

Probablemente hubo, como sugiere Caso, varios lugares del cielo en la tierra. El más famoso parece haber sido el referido por fray Gregorio García en su resumen del «Popol Vuh mixteco » : la morada de los primeros Ancestros divinos fue el « Lugar donde estaba el Cielo ", situado sobre una gran peña cerca de Apoala. En el pueblo se identifica con facilidad como el Cavua Caandihui, « Peña sobre la que está tendido el Cielo » o " Peña que sube al Cielo ", al Oriente del valle en que se ubica el actual Santiago Apoala (cf. Jansen 1982).

En los códices Vindobonensis (p. 48) y Nuttall (pp. 18 y 19), el Cielo aparece como un lugar sagrado de donde bajan los sacerdotes primordiales con los símbolos de poder (véanse Anders, Jansen \& Pérez Jiménez 1992a y 1992b ; Jansen 1997b). Se asemeja al concepto mazateco del Do Asean, el cielo oriental, origen de la luz, adonde se dirigen los chamanes en " vuelo mágico " para consultar con los Ancestros y los Dioses (Boege 1988). De ahí que encontramos a menudo referencias a Templos del Cielo, tanto en los códices históricos de la Mixteca (por ejemplo Nuttall, pp. 22 y 25), como en el Codex Borgia (pp. 33-34).

Una representación alternativa de las cuatro direcciones se encuentra en el Vaticanus B, p. 69, así como en Borgia, p. 27, pero los lugares se transforman bajo el simbolismo mántico que domina aquellos códices. Se trata de pronósticos para la cosecha. En este contexto el Oriente es la tierra fértil, pintada en forma de un gran lagarto.

2. - En la esquina izquierda superior está un valle entre dos montes principales, el Monte Partido y el llamado Monte de Ajedrez, en cuyas lomas se ven otros elementos toponímicos. Es interesante comparar este paisaje con su paralelo en Vindobonensis, p. 21 (Figura 2) : 


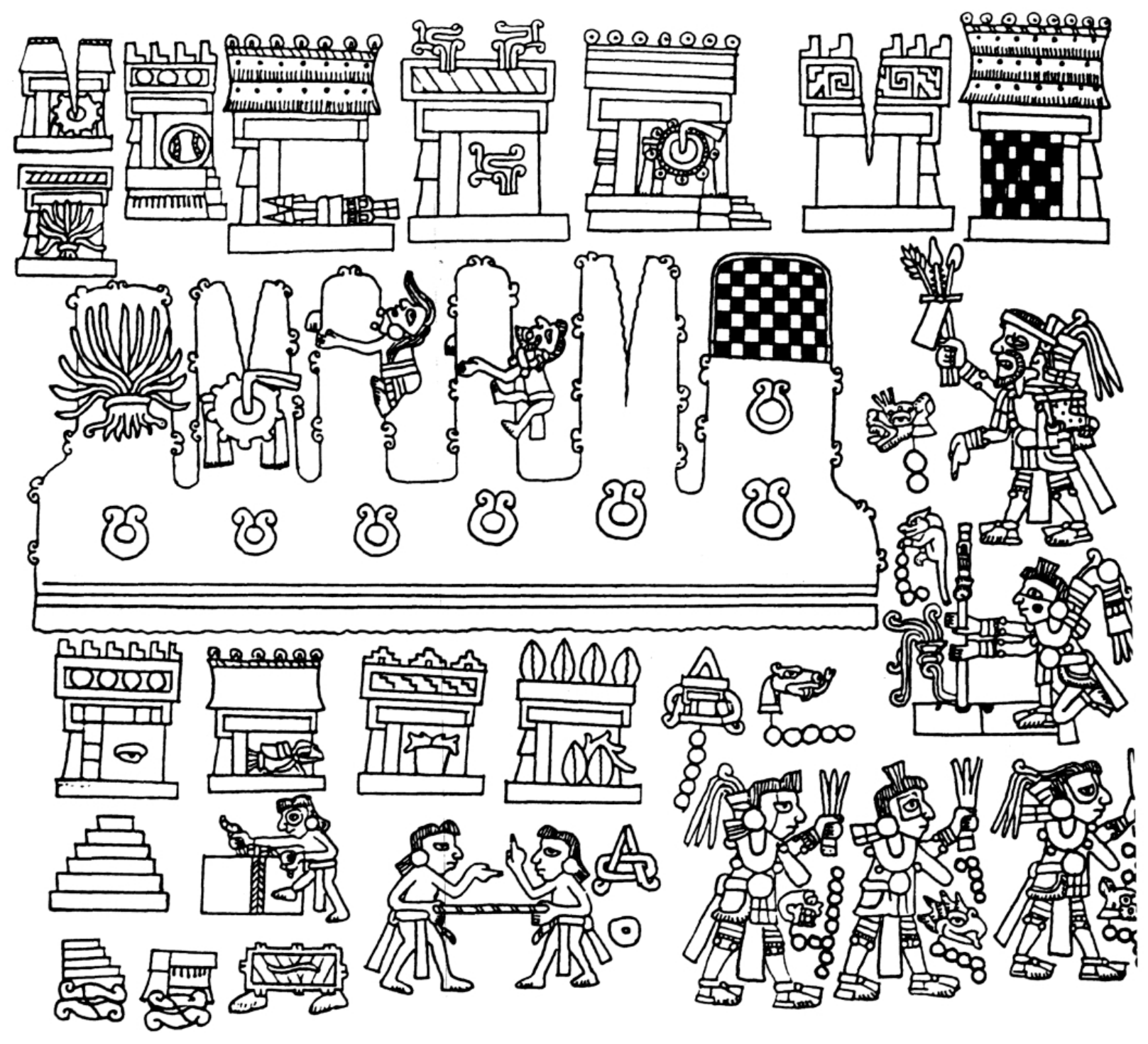

FIG. 2. - La ceremonia del Fuego Nuevo y la limpieza del paisaje del Norte, Codex Vindobonensis, p. 21. 


\begin{tabular}{|l|l|}
\hline \multicolumn{1}{|c|}{ MEX. 20 } & \multicolumn{1}{c|}{ VINDOBONENSIS, p. 21 } \\
1. Monte Partido & 1. Monte de Ajedrez \\
2. Monte de Humo y Polvo Verde & 2. Monte Partido \\
3. Monte de los Ancianos & 3. Montes de los Ancianos \\
4. Monte de Ajedrez & 4. Monte Partido del Tecomate de Tabaco \\
5. Monte de la Serpiente de Fuego & 5. Monte de Maguey \\
6. Siete Cuevas & 6. Gran Cueva con punzones del autosacrificio \\
\hline
\end{tabular}

Si adaptamos la secuencia, es evidente la correspondencia notable entre ambas listas :

\begin{tabular}{|l|l|}
\hline \multicolumn{1}{|c|}{ MEX. 20 } & \multicolumn{1}{c|}{ VINDOBONENSIS, P. 21 } \\
1. Monte Partido & 2. Monte Partido \\
2. Monte de Humo y Polvo Verde & 4. Monte Partido del Tecomate de Tabaco \\
3. Monte de los Ancianos & 3. Montes de los Ancianos \\
4. Monte de Ajedrez & 1. Monte de Ajedrez \\
5. Monte de la Serpiente de Fuego & 5. Monte de Maguey \\
6. Siete Cuevas & 6. Gran Cueva con punzones del autosacrificio \\
\hline
\end{tabular}

Probablemente el Monte de Humo y Polvo Verde y el Monte del Tecomate de Tabaco se refieren ambos a un Monte de Tabaco, cerca del Monte Partido. El tabaco o piciete es representado frecuentemente como un polvo verde en los códices mixtecos y funciona como un elemento para santificar y crear contacto con el mundo divino.

La equivalencia entre el Monte de la Serpiente de Fuego y el Monte de Maguey solamente se entiende en la lengua mixteca. El maguey es yavui y la serpiente de fuego representa el " hechicero que por los aires volaba », yahui. Aunque no podemos estar completamente seguros de ello, las palabras parecen suficientemente semejantes como para poder producir una variación en la escritura de un lugar lejano. Por otra parte es posible que la serpiente de fuego califique el Monte de Ajedrez como un « lugar de poder ", donde entran los nauales ${ }^{6}$.

Los otros códices muestran el Monte Partido y el Monte de Ajedrez como una versión abreviada. Según Alvarado, el término mixteco para " Norte» es Yucu naa, "Cerro Oscuro ». Interpretamos el tablero ajedrezado como representación de naa, " oscuro ». En el Vaticanus B, p. 69, vemos una representación similar del lugar del Norte en un contexto religioso : se pinta como una gran roca monstruosa, es decir una roca con alma y vida, y su color oscuro se indica por medio de bandas negras y grises ; el paralelo en Borgia, p. 27, aclara que se quiere enfatizar la tierra rocosa como pronóstico para la cosecha. El mismo sitio aparece en un contexto histórico en el Codex Nuttall, p. 51: la Montaña de Bandas Negras y Blancas, donde para el Señor 8 Venado antes de entrevistarse con el rey de los toltecas.

Buscamos este paisaje en la frontera norte de la Mixteca, en el área barrancosa de la Cordillera del Tentzon y el Río Atoyac, donde se ubican Tepeji (Monte Partido) y Huehuetlan (Lugar de los Ancianos). En el Mapa de Cuauhtinchan II el elemento toponímico que caracteriza esta cordillera es el Monte de Maguey ${ }^{7}$. Si éste es el monte 
mencionado por Vindobonensis y si este maguey es sustituido en el mex. 20 por la serpiente de fuego como un signo homónimo, debemos concluir que el mex. 20 es un manuscrito mixteco.

Este área septentrional es calificada por mex. 20 como una gran cueva con objetos de culto. En el Mapa de Cuauhtinchan I varias personas llegan a hacer ofrendas en una cueva del Tentzon. El Vindobonensis parece dar a esta cordillera del Norte el estatuto de un Chicomoztoc, "Lugar de las Siete Cuevas » o, mejor dicho, "Cueva Siete ", el sagrado lugar de origen ${ }^{8}$. Obviamente se trata de un concepto y se atribuía a varios lugares este estatuto de haber sido el del origen primordial. De hecho sospechamos que cada cueva de importancia religiosa podía ser considerada como un Chicomoztoc.

El término naa, " oscuro ", tiene una connotación simbólica similar, porque refiere a nuи naa, la época primordial de oscuridad y tinieblas, antes de que saliera el sol, antes de que hubiera días o años ( $c f$. Jansen 1997c).

3. - En la esquina izquierda inferior está un río con un montoncillo de ceniza. Lo mismo vemos en Vindobonensis, p. 16. Encontramos algunas variantes del signo, como : Altar de Ceniza (Lienzo de Tlapiltepec) o Río del Sol que Oscurece (Lienzo de Tequixtepec). Otros códices depictan un río sin ceniza. El término correspondiente registrado por Alvarado (s.v. Poniente y Viento del Poniente) es simplemente, Yuta, " Río », o, más específico : Yaa yuta, "Ceniza del Río ». Este topónimo apunta a la frontera occidental de la región mixteca, el río Nejapa, " Río de Ceniza ». Su patrona es la anciana Señora 1 Aguila, a la que podemos identificar como Yoco Sitna Yuta, "Diosa Abuela del Río », mencionada por la Relación Geográfica de Juxtlahuaca como la reponsable de « la multiplicación del género humano » (Relaciones geográficas 1984 , I, p. 185) ${ }^{9}$.

También en el Vaticanus B, p. 69, y en el Borgia, p. 27, el Poniente es representado por un río. La implicación mántica es la de una inundación que amenaza la cosecha.

4. - En la esquina derecha inferior está un Templo de la Muerte con un patio de sangre y corazones. Lo mismo vemos en Vindobonensis, p. 15. También los otros códices muestran un templo en forma de cráneo y otras partes esqueléticas. El término de Alvarado para « sur » es Huahi Cahi, "Casa amplia ». Este nombre se conoce bien hasta hoy día : Vehe Kihin es una cueva lúgubre, donde los ambiciosos van a pedir dinero, entregando su alma al demonio (" el Gachupín »). La traducción de " viento meridional ", que nos da Alvarado, confirma la asociación con el inframundo: tachi (a) ndaya significa literalmente «viento del lugar de los muertos ». Podemos identificar el gran Huahi Cahi de los códices como el sepulcro colectivo de los reyes mixtecos en una cueva cerca de Chalcatongo (Ñundaya, "Lugar de los Muertos »), en el extremo sur de la Mixteca Alta. Hoy día el sitio donde, según los habitantes del área de Chalcatongo, está la puerta hacia el Más Allá, donde se juntan los difuntos, es el Yucu Casa en los terrenos de Itundujia (parte del antiguo reino de Chalcatongo) : un monte impresionante, que domina las escarpadas bajadas de la Alta hacia la Costa ${ }^{10}$.

En Vaticanus B, p. 69, y en Borgia, p. 27, vemos otro signo, que representa la tierra seca, pero, en general, los manuscritos del Grupo Borgia asocian el Sur con el reino de la muerte. 
5. - El signo toponímico de la escena central ha sido muy dañado. En el mex. 21 y en la copia del Museo Nacional de Antropología distinguimos las fauces abiertas del gran lagarto que representa la tierra, flanqueadas por corazones. En el Codex Vindobonensis, p. 12, vemos algo similar : las fauces abiertas con un corazón y una corriente de sangre. Leemos este signo como " el corazón de la tierra », una expresión muy apta para denotar el centro. Las fauces abiertas connotan también la idea del nacimiento humano, como repetición del emerger de la tierra in illo tempore ${ }^{11}$.

Dentro de las fauces en mex. 20-21, según parece, hubo algo blanco con el motivo de puntos negros, como arena, ceniza o gotas negras : probablemente papel goteado con hule, un elemento bien conocido de los rituales mesoamericanos. En la escena del Vindobonensis las figuras asociadas son dos mujeres, identificadas como Diosas de Maíz por la flor de maíz que brota de su cabeza.

Sabemos que para la Mixteca Alta el centro religioso fue el oráculo de Achiutla, donde se veneraba " el corazón del pueblo ", un Envoltorio Sagrado, en una cueva (Burgoa 1934, I, pp. 319, 332-333) ${ }^{12}$.

La indicación del centro falta en la mayoría de las representaciones de los puntos cardinales. A veces es reemplazado por algún emblema del señorío a que se refiere el documento ${ }^{13}$. En el Codex Vaticanus B, p. 69, el centro es marcado por medio de las fauces del lagarto en combinación con dos huesos cruzados. En Borgia, p. 27, el lagarto se ha transformado en un recipiente precioso para el maíz. El signo de las fauces de la tierra con corazón vuelven a aparecer allí en otras páginas como fundamento de los grandes santuarios del centro ceremonial (Borgia, pp. 33-34). Esto significa probablemente que esos templos están construidos acorde con una orientación específica, según los ejes solsticiales, como ocurre con el famoso Castillo de Chichén Itzá (Freidel, Schele \& Parker 1993, p. 156).

Sospecho que los símbolos de los cuatro puntos cardinales provienen originalmente de una subdivisión vertical del cosmos en Cielo-Tierra-Inframundo, en la que la tierra, el nicho ecológico de la comunidad humana, es representada por el difrasismo «monte y agua » (yucu nduta en mixteco, altepetl en nauatl). El aspecto doble del término medio permitió una adaptación de esta estructura tripartita a una organización cuadripartita del plano horizontal : el cielo (Sol) se asoció con el Oriente, el monte con el Norte, el agua (río) con el Poniente, y el inframundo con el Sur. Luego los mixtecos escogían lugares concretos en la geografía real para representar estos conceptos elementales.

Así los jeroglíficos toponímicos sí corresponden a ciertos sitios en la realidad, pero a la vez no son simples elementos geográficos, sino que representan también las ideas asociadas con los puntos cardinales. Podemos describirlos como " lugares de poder » $\mathrm{o}$ « lugares-nauales ». En los códices religiosos se presentan en una forma generalizada como puntos de referencia para el simbolismo mántico. En los códices mixtecos y los lienzos del Valle de Coixtlahuaca tienen un carácter claramente geográfico y además ideológico : se mencionan en el contexto de la primera toma de posesión, de marcar un territorio, nombrar los lugares y encender el Fuego Nuevo. El contenido del Codex Vindobonensis concuerda con lo que hace constar fray Antonio de los Reyes en el prólogo de su Arte en Lengua Mixteca :

«En especial era tradición antigua, que los dichos señores que salieron de Apoala, se avian hecho quatro partes, y se dividieron de tal suerte que se apoderaron de toda la Mixteca. " 
Los topónimos en este conjunto no funcionan como asentamientos ni como cabeceras de cacicazgos, sino que marcan sitios simbólicos en la naturaleza que sirven como puntos de orientación sobre la tierra. A la vez remiten a la fundación primordial de los señoríos en las cuatro partes del mundo mixteco.

Oriente y Poniente son definidos por el movimiento del sol : el primero es el rumbo donde está la Casa del Sol, donde moran los hombres que han muerto en la guerra. De ahí su asociación con el sacrificio : los cuchillos en el mex. 20. En la parte occidental del cielo moran las mujeres que han muerto en el parto, de ahí que el Poniente está asociado con el poder feminino y con la fertilidad. El Norte constituye una frontera real con el ámbito de los nauas, pero a la vez es un lugar de culto, una cueva o roca oscura, asociada con el tiempo del origen. En el Sur está otra cueva, la del gran sepulcro y del poderío de la muerte ${ }^{14}$.

Bruce Byland y John Pohl han hecho una importante prospección arqueológica en el área de Tilantongo y Jaltepec, contribuyendo de manera significativa y valiosa a nuestro conocimiento de la distribución de los sitios precoloniales en esta parte de la Mixteca Alta. Buscando correspondencias entre sus hallazgos y las escenas pintadas en los códices mixtecos, sugieren que los lugares direccionales arriba descritos, se repiten en una escala menor en las alrededores de Tilantongo. En su favor aducen que el Señor 8 Venado visita estos sitios direccionales en el Codex Colombino-Becker en días consecutivos, de modo que, concluyen, éstos no pueden estar muy distantes (Pohl \& Byland 1990, p. 122). Esta interpretación es discutible, sin embargo. En dichas escenas el Señor 8 Venado hace culto a los árboles de las cuatro direcciones, no visita los lugares correspondientes, sino que realiza un ritual con referencia a ellos.

De todas maneras, Byland y Pohl sugieren que el Oriente es representado por el Templo del Sol (Yucu Gandi) en Achiutla, el Norte por el Monte Negro (Yucu Tnoo) junto a Tilantongo, el Poniente por Monte de Arena, Jaltepec, que interpretan como un « equivalente glífico » de Río de Ceniza, y el Sur por Mitlatongo. En cuanto a la boca de la serpiente, que representa el centro, la identifican como una cueva y sugieren que corresponde al Cavua Cuee, "Cueva de Enfermedad» en una barranca entre Tilantongo y Jaltepec (Byland \& Pohl 1994, pp. 82 sqq.; cf. Pohl \& Byland 1990, pp. 125 sqq.). Obviamente la ubicación de estos sitios en el espacio no refleja una estructura de los cuatro puntos cardinales : Jaltepec está al Oriente y Achiutla en el Poniente, mientras que no hay una línea Norte-Sur entre el Monte Negro y Mitlatongo, mucho menos con respecto al Cavua Cuee. Pero Byland y Pohl, recurriendo a la teoretización antropológica, observan :

« Clearly the four locations do no reflect " real "directional referencing [...] This may not be a significant factor in that other anthropologists have noted similar deviations in Native American directional precepts [...] The features are not recognized for their values with regard to true north but rather are employed in defining perceptions of community identity. " (Pohl \& Byland 1990, p. 126).

Tal teoría tiene validez en un nivel de abstracción general, pero no puede sustituir la falta de argumentos para una identificación concreta de los sitios aludidos. La mención de los nombres en el vocabulario de Alvarado no deja lugar a dudas de que se trate de marcadores generales de las cuatro direcciones. En este sentido un conjunto similar de términos direccionales aparece también entre las glosas del Codex de 
Yucunama (Jansen 1994, pp. 90-91). Ya que estos cuatro signos funcionan explícitamente como puntos de orientación en el lenguaje cotidiano, resulta difícil creer que no tuvieron una ubicación correspondiente en la geografía real. De no existir esta correspondencia, ¿cuál sería entonces la razón para identificarlos en el paisaje alrededor de Tilantongo ?

Byland y Pohl no toman en cuenta los nombres precisos de los puntos cardinales que nos da Alvarado. El Monte Negro (Yucu tnoo) no es lo mismo que el Monte Oscuro (Yucu naa). En el caso de Jaltepec se puede decir que la representación de arena (ñute) es similar, hasta idéntica, con la de ceniza (yaa), sin embargo se trata de otro topónimo. La boca del lagarto puede efectivamente representar una cueva, pero identificarla entre tantas cuevas con la de Cavua Cuee, es mera especulación.

Por más que la teoría de Byland y Pohl a primera vista parezca interesante, resulta, sin información adicional que la avale, demasiado hipotética y arbitraria, basada solamente en una similitud superficial entre algunos signos y algunos topónimos entre muchos signos y topónimos similares.

Otra teoría al respecto ha sido propuesta por Gordon Brotherston. En su estudio, ampliamente ilustrado, de una gran diversidad de documentos pictográficos, incluye una discusión del mex. 20 (Brotherston 1995, pp. 80, 101, 147-150). El valor de su libro consiste en que contribuye a dar una visión general de los temas literarios y patrones míticos en estos códices. Al contrario de Byland y Pohl, Brotherston se refiere a un área geográfica muy amplia. Entre las muchas ideas que presenta, hay asociaciones interesantes, pero también especulaciones discutibles e identificaciones de signos toponímicos que merecen un estudio más detenido. En cuanto a las identificaciones de las cuatro direcciones que he propuesto, Brotherston está de acuerdo con las de Nexapa para el Poniente y de Tepexic para el Norte. Para el Sur prefiere Mictlan, es decir Mitlatongo (Dzandaya), y para el Oriente Teotlillan. Aunque estos últimos dos lugares efectivamente pueden ser representados mediante los signos en cuestión, observamos que no hay información sobre el significado simbólico de Mitlatongo y Teotlillan para la Mixteca en general, comparable con los datos que tenemos sobre Chalcatongo y Apoala ${ }^{15}$.

El signo del centro, Brotherston lo identifica como una serpiente emplumada, que, en su opinión, ha de representar Coixtlahuaca, el Llano de Serpientes, por lo que procede a dar un nuevo nombre al mex. 20 : el de "Mapa de Coixtlahuaca ${ }^{16}$ ". Efectivamente muchos documentos con esta temática de los puntos cardinales proceden del Valle de Coixtlahuaca, pero esto en sí no es fundamento suficiente para identificar el signo central como esta ciudad. Efectivamente, Coixtlahuaca puede ser representada por una serpiente emplumada, y además se puede combinar con otro signo toponímico : una piedra con un motivo que parece ser un corazón (en el Lienzo de Tlapiltepec y el Lienzo Seler II). Aún así, se nota la diferencia entre esta representación y el Corazón de las Fauces de la Tierra. Por eso sigo pensando que este signo señala la idea del centro de la tierra, que para la vida religiosa de la Mixteca se situaba en Achiutla, pero que, para cada documento, puede haber sido un lugar diferente : la propia comunidad.

De toda esta discusión surge, entonces, el imperativo metodológico de que no se debe identificar un signo toponímico en aislamiento, sino siempre como parte de un conjunto. A los criterios de coherencia y correspondencia se auna el de significación : 
el conjunto identificado debe dar sentido en el contexto postulado. Nuestro método, en resumen, ha seguido los siguientes pasos :

1. - Establecer la estructura interna y el género de los signos toponímicos: forman parte de un conjunto que representa los puntos cardinales para la Mixteca Alta y áreas colindantes, tanto en un nivel geográfico real como en un nivel simbólico.

2. - Leer los signos de acuerdo con las convenciones pictográficas conocidas : con la ayuda del vocabulario de Alvarado se reconstruyen los nombres Andehui, Yucu Naa, Yaa Yuta y Huahi Cahi.

3. - Buscar lugares en el mapa que corresponden a esos nombres y se encuentran distribuidos en el espacio de tal manera que pueden haber servido para marcar los puntos cardinales : el río Nejapa es la frontera occidental y el área de Tepeji marca al punto más septentrional.

4. - Interpretar el valor simbólico con la ayuda de las fuentes históricas : el Lugar donde estaba el Cielo - sobre una peña junto al pueblo de Apoala - es mencionado explícitamente como lugar de origen sagrado, y la cueva del panteón de los reyes mixtecos en el señorío de Chalcatongo coincide con la idea del Sur como región de la muerte.

El simbolismo de las cuatro direcciones se vuelve a presentar de una manera especial en la biografía del Señor 8 Venado. Este héroe no sólo adora a los árboles de los puntos cardinales cuando sube al trono de un cacicazgo (en el Codex ColombinoBecker), sino que también sus actos históricos se realizan en relación con estos marcadores simbólicos. Como joven guerrero conquista la piedra preciosa del Poniente (Bodley, pp. 10-II). Junto con la Señora 6 Mono implora el apoyo de la guardiana espeluznante del Huahi Cahi (Nuttall, p. 44). Para forjar una alianza con los toltecas se sienta en el Monte Oscuro, la frontera entre la Mixteca y el área controlada por los nauatl-hablantes (Nuttall, p. 61). Como auge de su carrera acompaña al rey tolteca, Señor 4 Jaguar, Nacxitl Topiltzin Quetzalcoatl, en su campaña al Oriente, hasta llegar a la Casa del Sol, donde recibe las insignias de poder y experimenta una visión del futuro (Nuttall, pp. 78-79; Becker I, p. 4).

Obviamente la Casa del Sol es un concepto, el reino espiritual al que van los valientes que mueren en la guerra. El viaje al Sol es un motivo mítico que ocurre también fuera de Mesoamérica, por ejemplo entre los navajos (Reichard 1977, pp. 3749), y pertenece al tema clásico del viaje al Reino de los Muertos, tal como lo realizan Gilgamesh, Orfeo, Aeneas, Quetzalcoatl, Hunahpu e Ixbalanque, etc. Más que una prueba del valor temerario, se trata de un símbolo religioso y psicológico : el héroe cruza la última frontera, para entrar en el mundo divino, para explorar lo que hay más allá de lo consciente (Nortwick 1996, p. 28).

Por otra parte, los códices presentan la vida del Señor 8 Venado como una serie de eventos históricos, con una dimensión geográfica real. El contexto, especialmente su ubicación más allá de la Laguna de Términos (Nuttall, p. 75), sugiere que la Casa del Sol se situaba en la tierra de los mayas, como un sagrario específico, probablemente en Chichén Itzá (Jansen 1997a, 1997b).

Una vez más nos damos cuenta de que las entidades conceptuales pueden manifestarse en diversos lugares concretos. De ahí que los signos en cuestión se pueden 
comparar con los símbolos direccionales de los códices religiosos. En este aspecto es acertada la observación de Alfonso Caso, que reconcilia ambos aspectos - el geográfico y el simbólico - de estos topónimos, diciendo :

" Es frecuente en las tradiciones y en las religiones de muchos pueblos, hablar de lugares divinos que tienen el mismo nombre que otros lugares terrenos con los que en alguna forma están relacionados, como el Monte Olimpo, o la Jerusalén celestial o ya entre los mesoamericanos, lugares como Tamoanchan, Chicomoztoc y Tula que participan de la doble característica de ser lugares míticos y geográficos. » (Caso 1966, p. 189).

Es más, por el valor simbólico que se les atribuye, tales lugares se convierten en referentes emblemáticos de la identidad de una cultura o de un pueblo. Sin dejar de ser entidades físicas, se convierten en elementos constructivos de la colectividad social y espiritual ${ }^{17}$.

\section{Los DueÑos DEL Destino}

La correlación entre tiempo y espacio es muy característica del calendario mesoamericano. Por una parte esta organización es cognitiva, por otra puede tener su manifestación concreta en la geografía real. Por ejemplo, el tonalpoalli (la cuenta sagrada de los 260 días) consta de veinte periodos de trece días. Estas trecenas son organizadas en cuatro grupos, distribuidas hacia las cuatro direcciones, y luego divididas en dos segmentos de siete y seis o de ocho y cinco días cada una ( $c f$. Borgia, pp. 75-76, y Laud, pp. 9-16 respectivamente). Esto suena muy abstracto, pero en la vida ritual quiché hay sagrarios especiales del pueblo, dedicados al día 1 (junabal) y al día 8 (wajxakibal), que sirven para rezar y hacer ofrendas en los días que marcan esta división de las trecenas en siete y seis días - de modo que el primer segmento comienza con un día 1, y el segundo segmento con un día 8 (Tedlock 1982, pp. 59 sqq.). Así la estructura del tiempo se traduce en prácticas rituales y se manifiesta en lugares concretos.

Las cinco escenas del mex. 20 están enmarcadas en series de puntos rojos, que en los códices mánticos-rituales suelen indicar días consecutivos. Un paralelo sugestivo es la primera página del Codex Fejérváry-Mayer (que pertenece al Grupo Borgia), que muestra una composición similar (Figura 3) : una escena central es rodeada por cuatro escenas con símbolos direccionales, y el conjunto es enmarcado por bandas que empiezan con signos calendáricos (los primeros días de las trecenas), cada uno de los cuales es seguido por 12 puntos, que representan los demás días de cada trecena. Esta convención de encuadrar escenas con días se encuentra con frecuencia en los códices religiosos, para señalar la duración de un ritual (por ejemplo Borgia, p. 40) o el tiempo que está bajo la influencia de determinada deidad o imagen simbólica (por ejemplo Borgia, p. 73, y Vaticanus B, pp. 13-14) ${ }^{18}$. Algo similar se ve en los códices históricos donde los portadores de los años enmarcan una escena para indicar el paso del tiempo, por ejemplo el periodo que gobernó un rey (véase la historia azteca en el Codex Mendoza). Esta convención se asemeja a su vez a la banda celestial que rodea ciertas escenas en el arte mesoamericano para darles un carácter cósmico. 


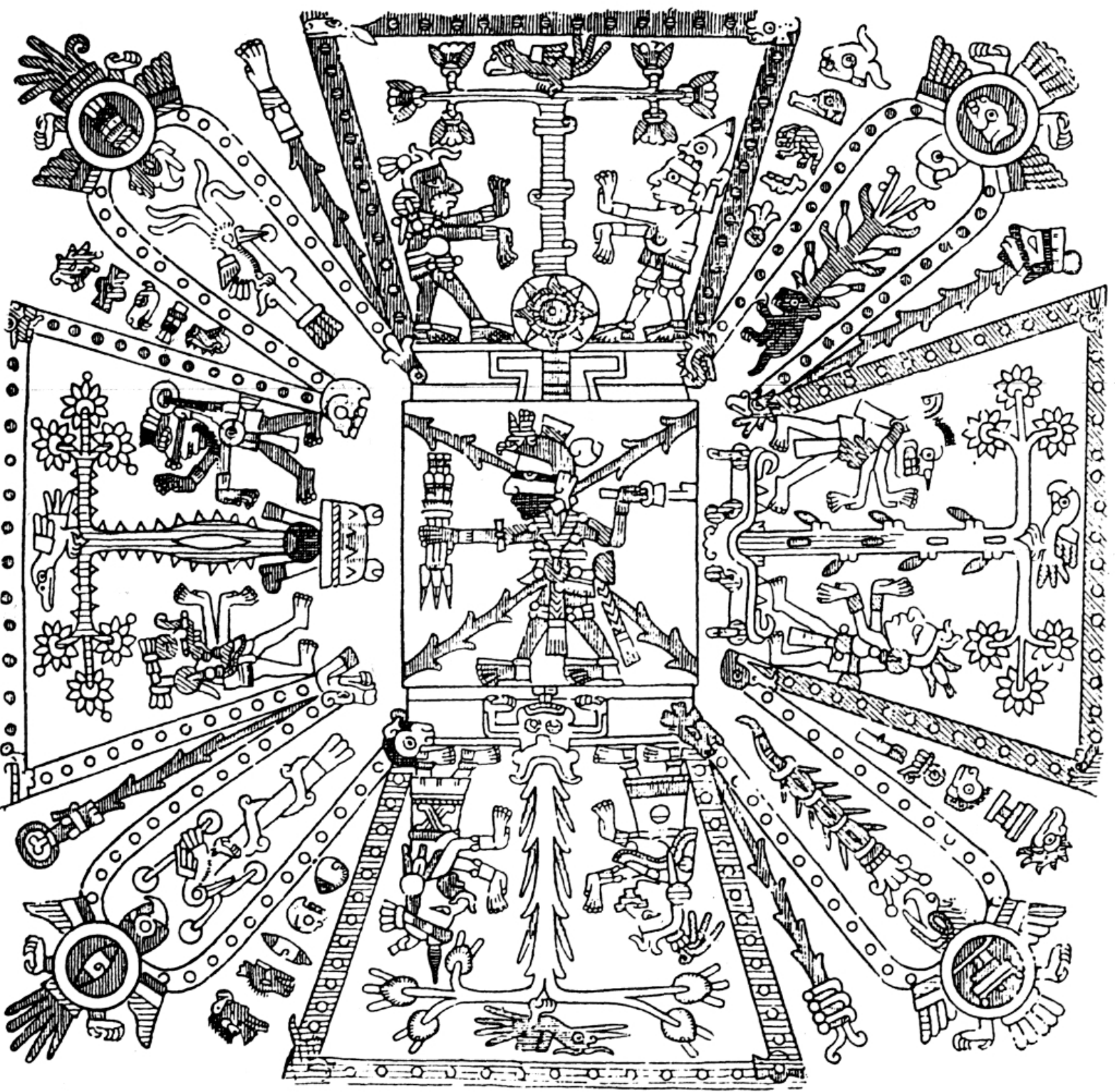

FIG. 3. - El cosmograma de las cuatro direcciones con sus árboles, aves y otros símbolos, como principio que organiza el calendario y los nueve Dioses de la Noche, Codex Fejérváry-Mayer, p. 1. 
En el mex. 20 vemos cinco series de 51 puntos cada una. Cada serie sigue un día insertado explícitamente al principio :

$\begin{array}{ll}\text { Oriente } & 5 \text { Lagartija (día } 44 \text { del tonalpoalli) } \\ \text { Norte } & 5 \text { Zopilote (día } 96 \text { del tonalpoalli) } \\ \text { Centro } & 5 \text { Conejo (día } 148 \text { del tonalpoalli) } \\ \text { Poniente } & 5 \text { Flor (día } 200 \text { del tonalpoalli) } \\ \text { Sur } & 5 \text { Hierba (día } 252 \text { del tonalpoalli) }\end{array}$

Todos estos días se ubican en las trecenas asociadas con el Sur, según las subdivisiones espacio-temporales del Grupo Borgia. Aquí marcan una organización de la cuenta sagrada de los 260 días en cinco segmentos de 52 días cada uno, comenzando desde el día 5 Lagartija. El mex. 20 muestra cómo estos cinco segmentos del tiempo son asociados con los puntos cardinales. La secuencia calendárica demuestra que la lectura debe ser : Oriente-Norte-Centro-Poniente-Sur, de modo que el centro geográfico también queda en el centro del ciclo de los 260 días.

Los cinco días mencionados no sólo inician segmentos de tiempo (indicados por los 51 puntos), sino que también son los nombres de los hombres que protagonizan las cinco escenas junto con una figura femenina, también identificada por un nombre calendárico de cada serie :
Oriente Sr. 5 Lagartija (día 44) y Sra. 1 Venado (día 27)
Norte Sr. 5 Zopilote (día 96) y Sra. 1 Lluvia (día 79)
Centro Sr. 5 Conejo (día 148) y Sra. 1 Mono (día 131)
Poniente Sr. 5 Flor (día 200) y Sra. 1 Casa (día 183)
Sur Sr. 5 Hierba (día 252) y Sra. 1 Aguila (día 235)

Las mismas cinco parejas, asociadas con las trecenas del Poniente y del Sur, se encuentran en el Codex Borgia, pp. 47-48 y en el Codex Vaticanus B, pp. 77-79. La relación entre los días de los nombres calendáricos de las Señoras y los de los Señores es constante, de modo que se distribuyen también en periodos de 52 días. De hecho son los días iniciales de las trecenas 3, 7, 11, 15 y 19, asociadas con el Poniente en el Grupo Borgia. Como ya observaron Lehmann y Seler, estos días son mencionados explícitamente por Sahagún (Libro IV) como característicos de las « Mujeres Divinas » (Ciuateteo) o " Mujeres Nobles » (Ciuapipiltin), es decir las mujeres que han muerto en el parto. Iconográficamente son manifestaciones de las diosas Tlazolteotl y Ciuacoatl Quilaztli ${ }^{19}$. Sahagún escribe que la genta temía que estas Ciuateteo « descendieran " en los días señalados (1 Venado, etc.), porque daban enfermedades a los niños y les paralizaban. Los médicos y las parteras eran muy devotos de sus signos (Sahagún, Libro IV, cap. 3, 11, 22, 27). Además :

« los que habían hecho algún voto o reverencia de ellas cubrían las imágenes de ellas con papeles en este día y ofrecían los papeles manchados con ulli y otros que no cubrían sus imágenes ofrecían comida y bebida y copal blanco y menudo. " (Sahagún, Libro Iv, cap. 33).

Los hombres combinan los rasgos de Macuilxochitl (5 Flor) y de Tezcatlipoca. Como estableció Notwotny (1961), se trata de los Tonalleque, o, mejor dicho, de los Macuiltonalleque, «los dueños del día con el número 5 "20. Todos son armados y ricamente ataviados. Donde las mujeres tienen una calavera en la parte trasera, ellos 
tienen una cabeza cortada (cabeza trofeo), con ojo cerrado, colgada de la parte delantera de su ceñidor o maxtlatl. Han de ser la contraparte de las mujeres divinas : los hombres heróicos, caídos en la guerra o sacrificados, que acompañan al Sol desde su salida en el Oriente y hasta su llegada al cenit :

« cuando el sol sale a la mañana vanle haciendo fiesta los hombres, hasta llegando al medio día, y luego las mujeres se aparejaban con sus armas, y de allí comenzaban a guiarle, haciéndole fiesta y recocijo ; todos aparejados de guerra dejábanle los hombres en la compañía de las mujeres, y de allí se esparcían por todo el cielo y los jardines de él, a chupar flores hasta otro día. Las mujeres partiendo de medio día iban haciendo fiesta al sol, descendiendo hasta el occidente... dejábanle donde se pone el sol, y de allí salían a recibirlo los del infierno y llevábanle al infierno. " (Sahagún, Libro vi, cap. 29).

En cuanto al análisis iconográfico de estas parejas, las contribuciones de Lehmann y Seler han sido fundamentales y - aparte de su enfoque astralista — siguen teniendo validez. Los autores modernos citados arriba no han dado tanta atención al carácter religioso del mex. 20. Byland y Pohl pasan por alto el significado de las parejas, mientras que Brotherston se limita a describirlas en términos generales como " the female and male Workers who occupy the fifth position in the set of Thirteen Heroes and who here celebrate military triumph» (1995, p. 148).

Las cinco parejas obviamente funcionan como protagonistas del texto pictográfico. La distribución por los puntos cardinales da a cada pareja una identidad propia que se manifiesta en ciertos detalles iconográficos. Observamos una oposición entre los Tonalleque del Oriente y del Poniente : son representados como Tezcatlipoca Negro y Tezcatlipoca Rojo respectivamente ( $c f$. Borgia, p. 21). El primero tiene una decoración de manos negras sobre tela blanca, el segundo una de manos blancas sobre tela roja ${ }^{21}$. El simbolismo de estos dos colores coincide con los conceptos de "frío » $\mathrm{y}$ " caliente ", que hasta hoy juegan un papel importante en la cosmovisión y medicina de los pueblos mesoamericanos. Curiosamente el color rojo, que representa la luz y el calor, aquí no viene asociado con el Oriente, sino con el Poniente.

También entre los Tonalleque del otro eje hay diferencias : el del Sur tiene los atributos de Mictlantecuhtli, el Dios de la Muerte, y el del Norte tiene un ornamento de plumas oscuras, propio de Quetzalcoatl, y carga en su espalda un objeto redondo que puede ser un envoltorio o un tecomate de tabaco. Se trata probablemente de la oposición binaria entre muerte y culto, que encontramos también en los signos toponímicos de estos puntos cardinales, así como en otros códices (Borgia, pp. 56 y 73 ; Fejérváry-Mayer, p. 1 ; Vindobonensis, p. 52).

El del Centro es una manifestación de Tecpatl o Iztli, el deificado Cuchillo: representa probablemente el sacrificio como actividad central en la vida humana (cf. Borgia, p. 32).

Para entender mejor su simbolismo hay que investigar la representación de estas parejas en otros códices. La escena de Borgia, pp. 47-48, muestra cómo los Tlazolteteo-Ciuateteo y Tonalleque proceden de cazuelas encimadas, de tal manera que una tapa a la otra. En el caso de las mujeres, su origen es precioso : una piedra verde en el interior de las dos cazuelas - la que está abajo es asociada con la muerte, la que la tapa tiene una cara viva y preciosa. Tlazolteotl es una Diosa de la procreación, de los partos y también de la muerte. Su manifestación es el algodón, atributo que la califica como Patrona del tejer, tanto en sentido literal como en sentido 
metafórico para las relaciones sexuales. La nariguera redonda colocada sobre telas rojas y negras es un atributo que comparte con los Dioses del pulque y de la borrachera ( $c f$. Codex Magliabechi, p. 48v sqq.). Junto con la mujer salen coralillos, cienpies y arañas, símbolos de vicios peligrosos, enfermedades y enredos.

El hombre sale de un cuchillo, colocado entre dos cazuelas rústicas, encimadas dentro de un espacio oscuro definido por huesos. Tiene el cuerpo distorcionado de Nanauatzin, el Buboso valiente que se convirtió en el Sol. Le acompañan serpientes y un perro, que respectivamente suelen simbolizar peligros y la combinación compleja de fieldad hasta la muerte y de comportamiento sexual indiscreto, sin vergüenza $^{22}$.

Aunque los elementos centrales de donde nacen las parejas son piedras duras y preciosas (pedernal y jade), las cazuelas encimadas (¿metáfora sexual ?) indican la fermentación de podredumbre. Estas escenas parecen simbolizar el origen de las impurezas, intrigas, enfermedades y de los demás peligros de la vida sexual. Luego se enumeran los cinco Tlazolteteo-Ciuateteo y Tonalleque, todos empuñando los objetos del autosacrificio, como prescripción ético-religiosa. La imagen sintetiza lo que las Parejas causan y lo que exigen, es decir lo que los humanos deben hacer para salvarse : las fuerzas divinas causan los problemas pero también los quitan, cuando los humanos cumplen con sus deberes rituales.

La desnudez de las Tlazolteteo-Ciuateteo enfatiza su asociación con la sexualidad. Sus ojos arrancados indican la ceguera y la muerte que pueden provocar. Sus punzones del autosacrificio están decorados con flores, indicación de que se trata de penitencia por excesos en la vida festiva y libertina. Otra clave para interpretar esta escena es la sangre que, en algunos casos, corre de su pecho o boca hacia un brasero. El Codex Telleriano-Remensis (p. $18 \mathrm{v}$ ) explica que las adúlteras cuando querían apartarse de su " pecado " iban de noche a las encrucijadas y allí sacrificaban sangre de su lengua a las Ciuateteo, dejando su ropa como signo de que dejaban su " pecado ». Serna (1953, p. 174) añade que las mujeres ofrendaban a las Ciuateteo "sangre sacada de debajo de la tetilla o de los ojos ». Esta sangre fue recogida en papeles, que a su vez fueron echados en braseros. Sahagún (Libro I, cap. 14) describe con detalle cómo en los días señalados se debía hacer una especie de " confesión de los pecados " ante estas " diosas de la carnalidad », haciendo penitencia y autosacrificio. El mismo autor (Libro I, cap. 12) explica que Macuilxochitl (5 Flor) era el Dios que castigaba con enfermedades venéreas a quienes le faltaban el respeto y no cumplían con el ayuno obligatorio.

La correspondencia de estos textos con las escenas de las parejas en el Borgia (pp. 48-48) y Vaticanus $B$ (pp. 77-79), sugiere que éstas señalan el tiempo adecuado para que mujeres y hombres hagan rituales de autosacrificio ante las Ciuateteo y los Tonalleque, con el fin principal de purificarse y de evitar enfermedades venéreas u otras posibles consecuencias negativas (ceguera, intriga, muerte) de la vida sexual. En los hombres la purificación parece ser una condición para transformar la potencia sexual en valentía y fuerza guerrera.

Los tiempos indicados para tales ritos de purificación, o « limpias », son el primer, quinto y décimo tercer día de las trecenas 3, 7, 11, 15 y 19 (las asociadas con el Poniente) para las mujeres y de las trecenas 4, 8, 12, 16 y 20 (las asociadas con el Sur) para los hombres. 
Las Ciuateteo del mex. 20 sostienen en su mano izquierda también los instrumentos de autosacrificio, colocados en una vasija o brasero, similar a lo que tienen frente a sí en las escenas del Borgia y del Vaticanus B. Hay entonces aquí también una referencia al aspecto de la purificación ritual.

Por otra parte, en mex. 20 la indumentaria de las parejas está claramente relacionada con la guerra. En la mano derecha las figuras femeninas tienen una cuerda (aztamecatl) y una bandera blanca, normalmente usadas para amarrar a un prisionero de guerra y ataviarlo para el sacrificio. Los hombres cargan escudos y una haz de flechas en la mano izquierda y una lanza con joyas en la derecha. Entendemos esto como el difrasismo « lanza y escudo » que significa " batalla " y "valentía " ${ }^{23}$. Las joyas suelen indicar la buena fortuna. Un detalle interesante es la mano en el escudo del Sr. 5 Lagartija (Oriente) : una referencia a la costumbre de cortar la mano de una mujer muerta en el parto, como objeto mágico para paralizar al adversario y así tener más éxito en la guerra, el robo o el juego (Sahagún, Libro VI, cap. 28-29).

La banda de cheurones que liga las escenas del mex. 20, se lee yecu, "guerra " o " enemigo" en mixteco (Smith 1973). El mismo motivo aparece con los signos direccionales en el Lienzo de Tlapiltepec y en el Rollo Selden. A la banda de cheurones en el mex. 20 se agregan otros signos, que refuerzan la referencia a la actividad de los guerreros.

- En el Oriente se ve un sol con pisadas. Se trata probablemente de la expresión "ir a la casa del sol ", como metáfora de "buscar fama ", ya que allí van los guerreros que mueren en la guerra (Sahagún, Libro vi, cap. 4, 21 y 33$)^{24}$. El resultado es el derrumbe de un gran templo, de donde salen llamas : una conquista importante.

- En el Norte vemos que un águila y un puma - símbolos conocidos de la valentía de los guerreros - son descabezados. Pertenecen a una ciudad con volutas y ceniza. Como ceniza es yaa en mixteco, esta combinación posiblemente se lee yaa, " canto ", y nos da la lectura " ciudades famosas ". Junto a la misma ciudad vemos la nariguera de Tlazolteotl y de los Dioses del Pulque : en este contexto puede simbolizar la braveza temeraria provocada por el alcohol. Las rayas temblorosas se leen tnañu, " guerra », en mixteco.

- Dentro del Río de Cenizas que representa el Poniente son flechados una serpiente de fuego y un caracol - ambos son símbolos del poder chamánico ( $c f$. Nuttall, pp. 44 y 50 ; véase también Jansen 1997b). Al lado una serie de flechas perforan el monte del puma : de nuevo se conquista la tierra de gente valiente. Pisadas señalan una campaña a un templo derrumbado y flechado, otro signo de conquistas.

- En el Sur se repite el templo flechado, derrumbado, en llamas. Junto a él está una calavera que come corazones, signo de la muerte.

- Como es lógico, el Centro no muestra escenas de violencia o conflicto : se trata de una guerra que sale del centro para hacer conquistas en las cuatro direcciones.

El aspecto guerrero se ve también en las páginas 49-52 del Codex Borgia, una serie de imágenes relacionadas con las cuatro direcciones y - a diferencia de la escena de Borgia, pp. 47-48 - combinadas con un tonalpoalli completo (organizado en 4 segmentos de 13 « columnas » de 5 días). Aquí las parejas bajan del cielo con : 1 . flechas 


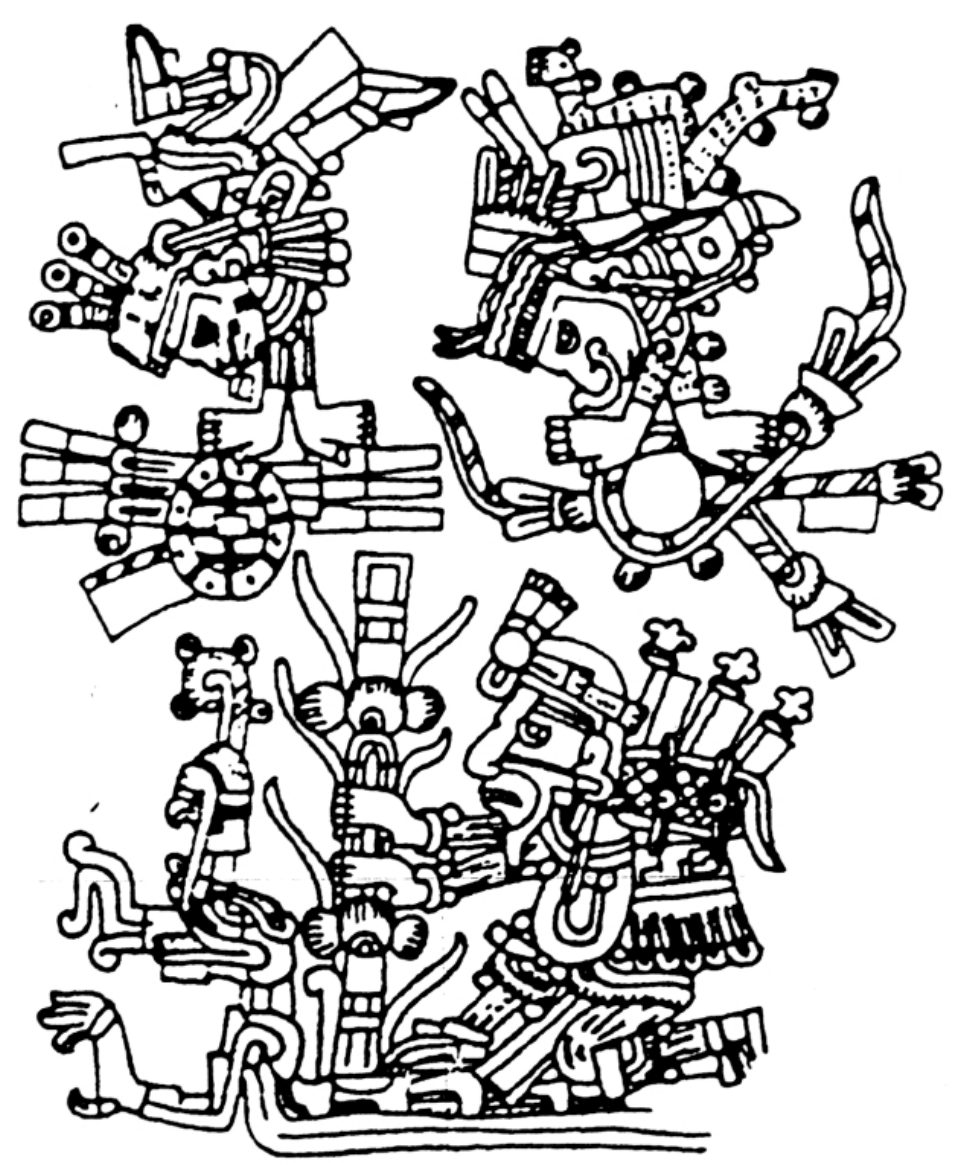

FIG. 4. - Macuilxochitl y Tlazolteotl bajan con armas y cuerdas para amarrar a los prisioneros de guerra, Codex Borgia, p. 49.

y cuerdas (conquistas, prisioneros) (Figura 4); 2. hacha, palo y piedra (violencia), agua y fuego (guerra) ; 3. pulque y maguey con banderitas (coraje embriagante, que resulta en sacrificios); y 4 . hacha, palo y piedra (violencia) ${ }^{25}$.

El aspecto guerrero de las parejas protagonistas viene aludido también en el Codex Borgia, p. 11, donde vemos al Tezcatlipoca Rojo con un brazo cortado en la mano, como patrón del día Aguila, y a Tlazolteotl como patrona del día Jaguar, los días en que nacen los valientes. De aquí sólo hay un paso a la temática del sacrificio humano : en Borgia, p. 41, vemos cómo sacerdotes de Tezcatlipoca y Ciuacoatl colaboran en la preparación de tal sacrificio, precisamente en los cinco días de las Ciuateteo: 1 Venado, 1 Lluvia, 1 Mono, 1 Casa y 1 Aguila.

Al igual que los topónimos, también las parejas tienen un paralelo en el Codex Vindobonensis. En varias páginas (51, 37 y 34) vemos a una mujer desnuda y un hombre desnudo de tipo Macuilxochitl (Figura 5), que esencialmente conforman a la misma pareja que la pareja a la que vemos cinco veces repetida en el mex. 20. El contexto sugiere que esta pareja funciona como una convención para señalar a los "Ancestros divinos". Esto nos lleva a pensar que las imágenes del mex. 20 combinan una referencia ética a los hombres y mujeres que obtienen el estatuto divino por enfrentar su destino, con una referencia idealizada a la división genérica de 
la sociedad. Los modelos del rol social son proyectados hacia la época de la creación y se convierten en los antepasados arquetípicos, responsables del órden geopolítico $^{26}$.

Estando firmemente paradas sobre los puntos cardinales las parejas se califican como "Dueños» y "Protectores », comparables con los Santos Patronos en la actualidad :

"Los santos patronos son ahora las entidades que simbolizan la vida espiritual colectiva, permitiendo que cada pueblo tenga un específico referente sagrado. Actúan como " aglutinadores simbólicos" de sus comunidades a las que amparan y representan, otorgándoles una filiación identitaria que conjuga el tiempo y espacio de la localidad, su historia y su territorio, con los de la colectividad social que la habita [...] La devoción por las deidades tutelares otorga a cada colectividad un componente identitario sacralizado y por lo tanto irreductible. " (Bartolomé 1997, pp. 104-105).

En este caso se trata de las manifestaciones direccionales de una pareja primordial, la Gran Madre y el Gran Padre, que cuidan toda la región identificada por los sitios de la fundación del mundo, los lugares de poder. Desde esta perspectiva se entiende que tanto los Tonalleque como las Ciuateteo tienen atributos que simbolizan no solamente la muerte, sino también el ciclo de la vida. A menudo brotan motivos vegetales de sus cabezas, probablemente como indicación de la bien documentada idea mesoamericana de que los grandes ancestros, después de su muerte, se transformaron en númenes de la naturaleza - piénsese por ejemplo en la representación de los antepasados en los lados del sarcófago de Ah Pacal, en la cripta del Templo de las Inscripciones, Palenque.

\section{LA INVOCACIÓN}

Es importante reflexionar sobre el género del mex. 20. Se trata de una sola hoja, organizada en forma de quincunx : cuatro escenas alrededor de una escena central. Brotherston interpreta el conjunto como la celebración del triunfo militar de Coixtlahuaca y la creación de un sistema de apoyo geopolítico de cuatro bastiones, fundada en un modelo cosmogónico :

"Through the paradigm of the quincunx itself, siege and mountain pillars, we move from imperial surface down into the earth's crust, a vaster claim in time and space. " (Brotherston 1995, p. 150).

Ya vimos que realmente no hay base para identificar el centro como Coixtlahuaca u otro lugar preciso y que el simbolismo de las cinco parejas es más complejo. Pero sí estamos de acuerdo con Brotherston para decir que la composición hace pensar en el cosmograma de la famosa primera página del Codex Fejérváry-Mayer (Figura 3), y, a la vez, en la fundamental estructura cuadripartita de la cosmovisión y de las ceremonias mesoamericanas. Es fácil visualizar cómo la hoja puede haber funcionado en el contexto de un ritual, como un plano, una " mesa ", que representa los campos de los poderes del mundo. Se puede pensar en la función de un lienzo sobre el que se puede tirar los maíces para adivinar la suerte ${ }^{27}$. Pero el contenido de la pintura es muy rico y nos obliga a interpretar su texto más allá del aspecto instrumental. 


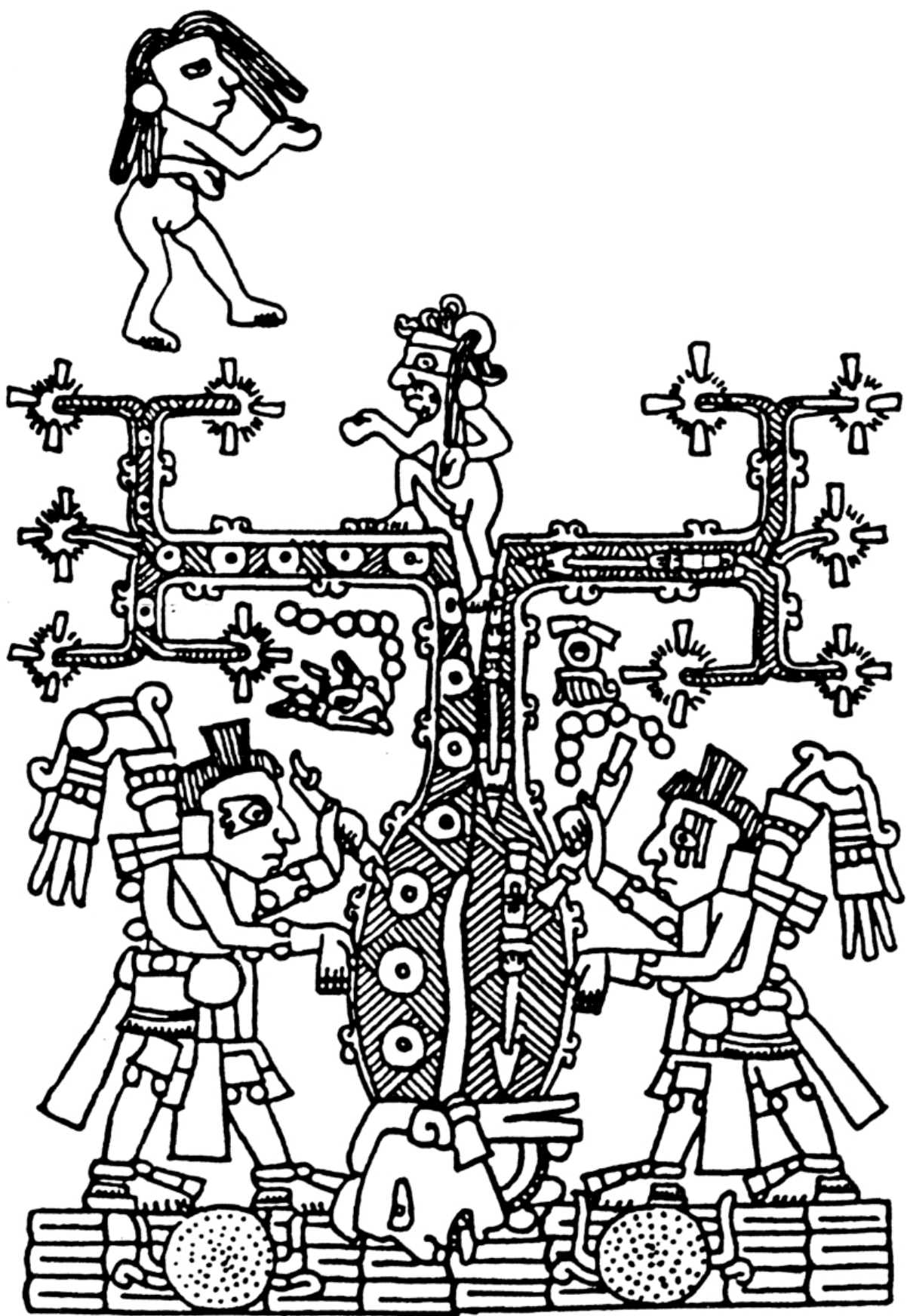

FIG. 5. - La pareja de Macuilxochitl y Tlazolteotl, indicando el título de " Ancestro divino ", Codex Vindobonensis, p. 37. 

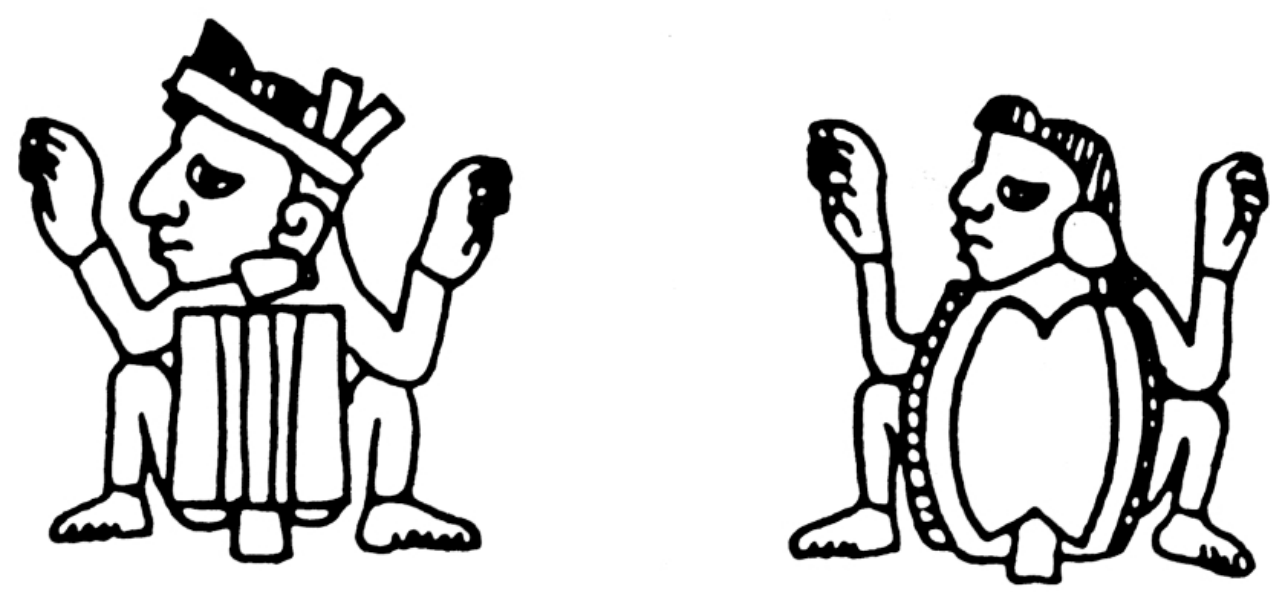

FIG. 6. - El sacerdote-naual en la posición de madre-padre, Codex Vindobonensis, pp. 51-50.

Además la comparación con los códices del Grupo Borgia demuestra que la estructura calendárica del mex. 20 no es la de una compleja operación mántica, y que no contiene los símbolos, generalmente ambivalentes, que suelen expresar los aspectos positivos y negativos del momento adivinado. La subdivisión del ciclo de los 260 días en cinco segmentos más bien se debe a la estructura dominante de la hoja pintada, que es geográfica : las cinco escenas se sitúan en cinco lugares. Ya vimos que los topónimos en cuestión representan el centro y las cuatro direcciones, y a la vez los sitios primordiales del mundo mixteco : suelen ser mencionados en textos y ritos que conmemoran la fundación de los señoríos.

Las escenas del mex. 20 no son narrativas ni conmemorativas, es decir que no son históricas, sino expresan ideas acerca de la organización del cosmos. Nuestro manuscrito pertenece al "género prescriptivo", pero la énfasis no está puesta sobre el aspecto mántico-adivinatorio. Más bien su visión de la conexión de tiempo, espacio y fuerzas divinas puede servir para estructurar ideas, ritos y textos. De ahí que interpretamos esta pintura como un punto de partida para la meditación, la celebración de ritos y la formulación de textos religiosos, es decir de rezos y conjuros.

Este idea encuentra apoyo en las correspondencias con el Codex Vindobonensis, que es un largo texto florido (" parangón ») sobre el origen de las dinastías mixtecas, pronunciado tal vez durante la ceremonia de entronización de los reyes de Tilantongo.

Los protagonistas del mex. 20, la Mujer y el Hombre ejemplares, deificados como la Pareja Ancestral, aparecen como puntos focales de ritos de purificación. Pensando en las «limpias» actuales en la Mixteca ( $c f$. Jansen 1982, p. 171 ss ; Bade 1994), interpretamos la purificación como un acto de restaurar el estado original de la persona y de darle fuerza espiritual para superar traumas y armarse de valor contra los peligros de la vida. Encontramos un ejemplo concreto de ello en la invocación mexica de la diosa Ciuacoatl Quilaztli, en su aspecto guerrero, como Madre simbólica y ejemplo divino de la mujer que da a luz :

"Señora e hija mía, habéis trabajado, habéis afanado, habéis seguido a vuestra madre Cihuacoatl, la señora Quilaztli ; habéis peleado varonilmente con la rodela y con la espada ; ahora ya habéis echado aparte con la ayuda de nuestro señor la pelea mortal del parto..." " (Sahagún, Libro VI, cap. 35). 
Los discursos pronunciados con ocasión del parto contienen muchas referencias al mismo simbolismo que desempeña un papel importante en la pintura del mex. 20. Las luchas de los ancestros son recordadas al recién nacido para señalarle su destino y darle ánimo para cumplirlo :

« aquí brotarás, aquí floreces, aquí te apartas de tu madre, como el pedazo de piedra donde se corta [...] tu propia tierra, otra es, en otra parte estás prometido, que es el campo donde se hacen las guerras [...] tu oficio y facultad es la guerra, tu oficio es dar a beber al sol con sangre de los enemigos [...] Tu propia tierra, y tu heredad, y tu padre, es la casa del sol, en el cielo... » (Sahagún, Libro VI, cap. 31).

Luego el mismo discurso conecta esta idea con el llamamiento ético y social de vivir en pureza y piedad. Se mencionan explicitamente los objetos del autosacrificio tales como se ven en el mex. 20 :

« esta la ofrenda de espina, y de maguey, y de caña de humo, y de ramos de acxoyatl, la cual se corta de tu cuerpo, cosa muy preciosa ; con esta ofrenda se confirma tu penitencia y tu voto, y ahora resta que esperemos el merecimiento y dignidad o provecho que nos vendrá de tu vida y de tus obras; hijo mío muy amado, vive y trabaja... " (Sahagún, Libro vi, cap. 31).

Tales expresiones y referencias no se limitan al contexto del parto. En la obra de Hernán Ruiz de Alarcón, que es un registro sumamente valioso de ritos y textos religiosos, los Macuiltonalleque, « Dueños de los días 5 » aparecen como naualtocaitl, el nombre mágico, de los cinco dedos del curandero y son invocados a menudo : para hacer la nasa (Tratado II, cap. 14), para curar (Tratado VI, cap. 1, 7 y 13), para adivinar (Tratado v, cap. 1 y 2), etc ${ }^{28}$. Para hacer redes de caza las manos deben colaborar con los hilos del tejido : por eso los Macuiltonalleque y Ciuacoatl son invocados conjuntamente (Ruiz de Alarcón, Tratado II, cap. 8).

En una ceremonia para curar los males que proceden de amores ilícitos el curandero habla al fuego y al agua del baño :

"Tla xihualhuia ayauhtli itzon, poctli itzon nonan [dice : nopan] chalchicueye iztacihuatl.

Tlaxihualhuian in antlaçolteteo,

in tiquato, in ticaxoch, in titlahui, in tixapel, etc. "

"Venga, pelo de niebla, pelo de humo (espíritu del fuego),

mi madre Falda de Jade (espíritu del agua), Iztacciuatl (el volcán),

vengan Ustedes, manifestaciones de Tlazolteotl,

tú Quato, tú Caxoch, tú Tlahui, tú Xapel, etc. "

(Ruiz de Alarcón, Tratado IV, cap. 3) ${ }^{29}$

Poco después en el mismo rito se combina la invocación de estas manifestaciones de Tlazolteotl con la de los Tonalleque :
"Tla xihualhuian macuiltonalleque,
Vengan, Dueños de los días 5, in tiquato, in ticaxoch...
tú Quato, tú Caxoch... »

En muchos conjuros encontramos una invocación de los poderes divinos de las cuatro direcciones. Contra asaltantes de caminos, por ejemplo, se reza : 
"Tlaxihuallauh olloque yaoyoque

in ihuan tlahuitequi, in ihuan tlatzotzona, tlaxihualhuian tlamacazque

tonatiuh iquiçayan, tonatiuh icalaquian, in ixquichca nemi,

in yolli, in patlatinemi, inic nauhcan niquintzatzilia, yc axcan yez.
Vengan dueños de la pelota y de la guerra, que juntamente hieren y golpean, vengan espíritus, del Oriente y del Occidente, dondequiera que viven, los seres vivos, los que vuelan. Con que les invoco de las cuatro direcciones, por esto ahora será. » (Ruiz de Alarcón, Tratado II, cap. 1)

El invocador se identifica como sacerdote espiritado (tlamacazqui) y se dirige a los que igualmente son espíritus (tlamacazqui) en las cuatro direcciones :

\author{
In antlamacazque, \\ in nauhcampa amonoque, \\ in nahuianpa in ancate : \\ amixpan anmomatian \\ in onihualla, in onecoc \\ in nitlamacazqui.
}

\author{
Ustedes, los espíritus \\ que están en las cuatro partes del mundo, \\ que se encuentran en las cuatro direcciones, \\ con su permiso y su consentimiento \\ he venido y llegado, \\ yo el sacerdote espiritado. \\ (Ruiz de Alarcón, Tratado II, cap. 8)
}

Por su importancia para sus clientes y para la comunidad en general, el sacerdote mesoamericano también se designa como "madre y padre ", que a su vez invoca al Padre y Madre, es decir a los Ancestros deificados. "Vine, yo el Padre-Madre (tayiwua, tasi' $i$ ), a la casa de nuestro Padre (yiwuandi), a la casa de nuestra Madre (si'indi) » reza el curandero mixteco (Schultze Jena 1933-1938, III, p. 86) ${ }^{30}$. Sospecho que este título del sacerdote chamánico es referido en el Codex Vindobonensis (pp. 50-51), donde vemos a un hombre, untado de negro como un sacerdote, sentado en cuclillas como una parturienta, cubierto con el caparazón de una tortuga (parte de la indumentaria de la serpiente de fuego, es decir del sacerdote-naual) : véase Figura 6.

Por todo lo dicho arriba pensamos que la pintura del mex. 20 se debe entender como un texto pensado o pronunciado por un "madre-padre " (sacerdote chamánico) que se dirige a los Ancestros Divinos, Madres y Padres, en las cuatro direcciones y el centro, en los mismos lugares-nauales donde Ellos en la época primordial marcaron los linderos del territorio mixteco. A este papel protagónico del chamán se debe, pensamos, el hecho de que las figuras en el centro del mex. 20 están paradas en un recinto almenado, es decir en el patio de un sagrario, y miran hacia arriba : están invocando a los poderes superiores.

Los elementos iconográficos asociados permiten reconstruir los objetivos de la plegaria. El enlace temático entre las escenas es la banda de cheurones, la guerra (уесu). Como tal este signo es el equivalente de los signos asociados con los puntos cardinales en otros códices : ritos del Fuego Nuevo (Vindobonensis), aves (Lienzo de Tequixtepec, Codex Gómez de Orozco) o árboles (Colombino-Becker) - signos que se encuentran también en el Grupo Borgia, a menudo combinados con deidades y templos direccionales (cf. Fejérváry-Mayer, p. 1, y Borgia, pp. 49-53).

Estamos ante un simbolismo complejo que conecta la idea del orden cósmico con la de su fundación in illo tempore. Los árboles direccionales recuerdan el levantar de 
los árboles primordiales que sostienen el universo y las ceremonias del Fuego Nuevo conmemoran la primera salida del sol, la primera luz que marca el tiempo en que actúan los humanos. La guerra de los Ancestros es la victoria primordial de los humanos sobre los seres de la época oscura ${ }^{31}$.

Esto sugiere que el texto del mex. 20 invoca la fuerza de los Antepasados, que ahora son los Dueños espirituales de los puntos cardinales, como una preparación para la guerra. Pero ya vimos que la guerra no sólo se refiere al conflicto armado real, sino que también aparece como metáfora para el parto. En un sentido general la entendemos como "la lucha ", el esfuerzo para superar el conjunto de trabajos, sustos y dificultades que es la vida. Por eso, el texto del mex. 20 es aplicable en varios contextos y podemos reconstruir su función en un ritual similar a la "limpia " que se sigue practicando hasta hoy día. Ante un trauma, una crisis o un momento decisivo, la mente se centra (en el corazón de la tierra) y reflexiona sobre las raíces de la comunidad : al ubicarse dentro del orden cósmico y al dirigirse a los Ancestros y a los marcadores sagrados del territorio original, se invoca la identidad profunda de la comunidad, se restablece la armonía y se revivifica la persona $^{32}$.

Mejor que un análisis teórico, el rezo de un curandero y sabio actual capta el significado del mex. 20 :

" Ave María, Madre mía, empiezo a invocar y mencionar a todos los confines del mundo para sanar sus males y dejar blanco, tierno y lozano su espíritu, para aliviarlo, sanarlo de todo, me dispongo a buscar e indagar por mis propios ojos, por todos los rincones, desde donde están las aguas de los mares, las madres de los rayos, desde donde están los puertos de los cielos, de los montes [...] todos los extremos del mundo [...]

me dispongo a normalizar su vida, su cuerpo, su alma, invocando los doce padres y madres que los muevo, los levanto y les ofrezco lo sabroso, lo dulce, lo agrio, lo frío y lo caliente para pedirles su gracia [...] Hasta donde está la raíz de los mares, las arenas secas, la raíz de los vientos, hasta las puertas del cielo, de la gloria, doce mujeres de los relámpagos, doce mujeres de los rayos $[\ldots]$

invocando los doce padres y doce madres que muevo para esto, para traer su espíritu tierno, bueno y puro, animales, pájaros, nahuales de tigre, leones, faisanes, palomas, me dispongo a juntar a todos para el alivio de su espíritu tierno, bueno y puro, me dispongo a visitar todos los montes, todos los ríos, todos los planos de la tierra, de las aguas, de la vida y de todo el mundo... " (Boege 1988, pp. 194-195).

Aquí se impone una comparación con las pinturas de arena (sandpaintings) de los navajos, que son usadas en un contexto similar (Reichard 1974, 1977). La semejanza formal se nota en la composición de cuatro escenas repetitivas (pero distintas en colores y otros detalles) alrededor de un centro. Generalmente una representación del arco iris rodea la pintura, ocupando el lugar de la banda del tonalpoalli o la banda celestial en el arte mesoamericano. Dichas pinturas se combinan con incantaciones (chants), revelan la misma idea de purificación y poder (poder para matar y para restaurar la vida) y contienen referencias similares a los seres de la época primordial, a las cuatro direcciones y a los lugares sagrados ${ }^{33}$. Funcionan en rituales elaborados, cuyo fin principal suele ser curativo. Otros objetos usados en este contexto también aparecen en los códices mixtecos, como el Envoltorio, el haz sagrado de varitas sagradas (prayer sticks) y el instrumento para hacer fuego. 
En vista de estos paralelos y de su propio contenido postulamos entonces que el mex. 20 es un documento ritual, una « hoja de poder » que funcionaba como base de una incantación. Es probable que algunas otras pinturas del Grupo Borgia, como el citado cosmograma del Fejérváry-Mayer (p. 1) o la escena de los cinco manifestaciones del Dios de la Lluvia (Vaticanus B, p. 69 ; Borgia, p. 27), tuvieron una función similar.

Aunque debemos estar conscientes de que la pictografía es otro medio que la fonografía, tal como una pintura o película es otro medio que un libro, aprendimos del análisis de los códices mexicanos que es posible - y muy productivo - leerlos como textos, acorde con las convenciones pictográficas y las connotaciones simbólicas. Aplicando este método al mex. 20, podemos reconstruir una « lectura » rudimentaria, que naturalmente es especulativa pero que tiene sus bases en las consideraciones expuestas arriba :

« Vine yo, el madre-padre, y me dirijo a Ustedes, Grandes Madres, Grandes Padres, Mujeres Divinas, muertas en el parto, Ciuateteo, manifestaciones de Tlazolteotl Yollotlicue y de Ciuacoatl Quilaztli,

y Guerreros Divinos, muertos en la batalla, Tonalleque, manifestaciones de Tezcatlipoca, el Señor omnipresente e impalpable, que cuidan las cinco partes del año sagrado, que se encuentran en los lugares de poder que desde su origen marcan el territorio de nuestro pueblo.

Hacemos penitencia ante Ustedes, para purificarnos, para que nos den fuerza y valentía, para tener buena fortuna en la guerra, para agarrar nuestros adversarios y sacrificarlos, para tener una vida limpia, para recibir y criar bien a nuestros hijos. Rezo, llamo a las cuatro direcciones y al centro.

Vengan, Grandes Espíritus del Oriente, de donde sale el Sol, del Lugar donde está el Cielo, Apoala, origen del poder de los reyes y chamanes, vengan, Señora del día 1 Venado y Señor del día 5 Lagartija, con el poder de la Madre Purificadora, con el poder del Tezcatlipoca Negro, para que Ustedes nos den la fuerza para ir al Sol y conquistar el Templo Precioso, o sea para triunfar en la vida y ganar fama.

Vengan, Grandes Espíritus del Norte, del Monte Partido - Monte Oscuro, en el área de Tepeji, donde colindamos con los nauas, del lugar de la cueva de origen, de culto a la tierra, vengan, Señora del día 1 Lluvia y Señor del día 5 Zopilote, con el poder de la Madre Purificadora, con el poder de Tezcatlipoca, el Sacerdote primordial, para que Ustedes nos den fuerza para vencer completamente a los pumas y águilas, los valientes, de las ciudades famosas.

Vengan, Grandes Espíritus del Centro, del Corazón de la Tierra, vengan, Señora del día 1 Mono y Señor del día 5 Conejo, con el poder de la Madre Purificadora, 
con el poder de Tezcatlipoca que se manifiesta en el divino Cuchillo, para que Ustedes nos den fuerza para realizar los sacrificios.

Vengan, Grandes Espíritus del Poniente, del Río de Ceniza, del Río Nejapa, de la frontera occidental, vengan, Señora del día 1 Casa y Señor del día 5 Flor, con el poder de la Madre Purificadora, con el poder del Tezcatlipoca Rojo, para que Ustedes nos den fuerza para vencer hasta a los poderosos chamanes, para flechar los cerros de los valientes, para hacer campañas de guerra, conquistar pueblos y regresar.

Vengan, Grandes Espíritus del Sur, del Templo de la Muerte, con su patio de sangre y corazones, del Vehe Kihin de Chalcatongo (donde están sepultados nuestros reyes), vengan, Señora del día 1 Aguila y Señor del día 5 Hierba, con el poder de la Madre Purificadora, con el poder de las deidades de la muerte, para que Ustedes nos den fuerza para conquistar los pueblos, y pasar por donde la muerte come el corazón.

Vengan, Ancestros preciosos, que nos han dado vida, dénos ahora la fuerza para superar la muerte, como las plantas que vuelven a brotar de la tierra, y siempre florecen de nuevo. »

Encontramos una posible referencia histórica a este ritual del mex. 20 en el Codex Selden (p. 7-Iv) : véase Figura 7. Este manuscrito pictórico de Jaltepec relata cómo la princesa mixteca 6 Mono implora la ayuda de la Dueña del Templo de la Muerte (Vehe Kihin). El tópico de la conversación es representado por el signo de cuatro volutas amarradas, que ha de representar el acto ritual de hablar a las cuatro direcciones, combinado con la banda de cheurones, es decir yecu, "guerra ". Una línea negra conecta este complejo signo con armas y la tabla para hacer el Fuego Nuevo. Efectivamente se estaba preparando una batalla de significado histórico : estaba en juego la continuación de la dinastía ${ }^{34}$.

Pienso que el signo de las cuatro volutas con la banda de cheurones representa el tipo de rito para el cual se empleaba el mex. 20. Es un caso concreto de la plegaria a las fuerzas de los puntos cardinales (aquí pronunciada ante la Señora del Sur), para obtener su apoyo en un conflicto armado. Hay que tomar en cuenta que el encuentro en el Vehe Kihin fue una experiencia visionaria, un viaje en trance. Probablemente se usaban alucinógenos para causar tal estado mental ( $c f$. Furst 1980, de la Garza 1990), pero estos medios no eran lo que interesaba a los mesoamericanos y rara vez se mencionan explícitamente.

En total contraste con los que usan drogas como vicio para el placer individual o para matar el tiempo, el sacerdote-curandero mesoamericano se siente responsable para el bien común y se esfuerza para curar a la gente que sufre ${ }^{35}$. Su poder se deriva de una rigurosa disciplina mental. Para ser digno de establecer contacto con las fuerzas primordiales, el sabio se prepara con humildad y suma concentración. Lejos de cualquier sensacionalismo, se serena y se purifica a través de abstinencia, ayuno y 


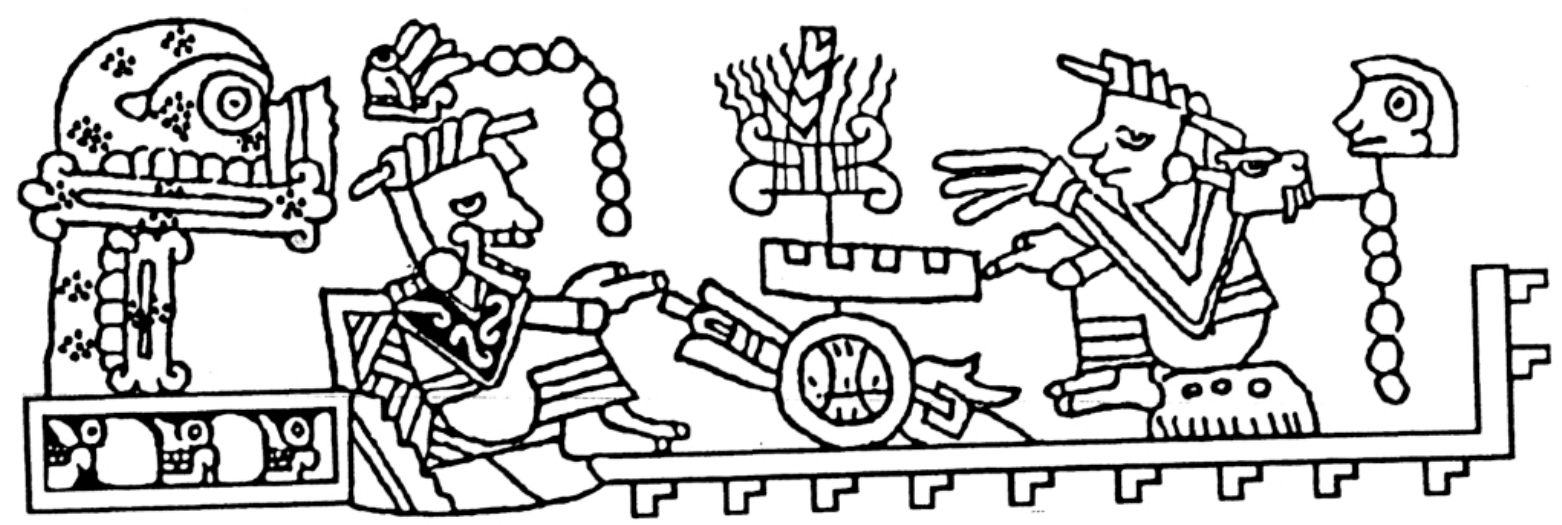

FIG. 7. - La princesa 6 Mono de Jaltepec invoca las cuatro direcciones para la guerra, ante la Señora 9 Hierba del Templo de la Muerte, Codex Selden, p. 7-IV.

autosacrificio. En repetidos actos rituales y rezos expresa su respeto y se rinde a los ritmos del Otro Mundo. Entonces, como dice la sabia mazateca María Sabina :

« No es necesario cerrar los ojos, basta con ver hacia el fondo infinito de la oscuridad : allí aparecen los Seres Principales alrededor de la mesa sobre que existen todas las cosas del mundo. » (Estrada 1977, p. 118).

\section{NOTAS}

1. Este trabajo es parte del proyecto de investigación que mi esposa y colaboradora Gabina Aurora Pérez Jiménez y yo desarrollamos en la sección América Indígena de la facultad de arqueología de la universidad de Leiden. Las orientaciones de Benedikt Harmann, Ferdinand Anders, Jarich Oosten, Miguel Bartolomé y Luis Reyes García me han guiado en el estudio de la religión mesoamericana. Debo mucha inspiración al contacto continuo con colaboradores y estudiantes, especialmente aquellos que participan en el programa de postgrado, entre ellos : Nick Caretta, Bas van Doesburg, Ruud van Akkeren y Michel Oudijk.

2. El censo de Glass \& Robertson (1975) resume los datos codicológicos y bibliográficos de este manuscrito así como de los demás códices mencionados aquí. Caso (1966) publicó fotos en color del original del mex. 20 y de la copia del Museo Nacional de Antropología ( $c f$. Glass 1964). Para una reproducción a color del manuscrito fonds mexicain 21, véase, por ejemplo, el catálogo Aztlan, terre des Aztèques, de la Bibliothèque nationale (1976). Es curioso que Boturini no mencione « ídolos » en la parte central, sino sólo en las cuatro esquinas : si en su época ya no se veía bien la escena en el centro del original, no se explica a base de cuáles datos se pintaron las copias. Un exhaustivo análisis descriptivo del mex. 20 y sus copias fue presentado por Simonin (1998) que incluye fotos a color y nuevo dibujo.

3. Para un examen del ahora obsoleto astralismo y del cambio paradigmático en la interpretación de los códices mexicanos, véanse Loo 1987 y Anders, Jansen \& Pérez Jiménez 1994.

4. La identificación de Monte que se Abre/Insecto como Monte Albán se menciona en un artículo anterior (Jansen \& Pérez Jiménez 1998). Una idea general de la historiografía del Valle de Coixtlahuaca se encuentra en Doesburg \& Buren 1997. Véanse también los estudios de Caso (1961) y Parmenter (1982). La historia del Codex de Tututepetongo ha sido aclarada de manera admirable por Doesburg en su disertación (1996) ; un breve comentario sobre la parte religiosa se encuentra en Anders \& Jansen 1994.

5. Para la lectura original del ñuhu, véase Smith 1973, y para una elaboración de este descubrimiento, véase Jansen 1982, p. 295 sqq. En la primera página del Vindobonensis (p. 52) encontramos los signos de " ñuhu que emerge de la tierra " y " ñuhu que baja y se mete en la tierra " : probablemente representan la salida y el ocaso del sol (Oriente y Poniente), así como el ciclo de vida y muerte. 
6. El nombre mixteco de la serpiente de fuego fue descifrado por Smith (1973). Hay que distinguir bien entre semejanzas fonéticas, que pueden causar representaciones pictóricas alternativas de un determinado topónimo, y asociaciones conceptuales. Véase la discusión sobre el yahui en Jansen 1997b, pp. 76-79.

7. Para los mapas de Cuauhtinchan, véase la publicación de Yoneda (1981). La lectura del Monte Partido como Tepeji es lógica para conocedores del nauatl. Siguiendo al astralismo de Seler, Hermann Beyer, en una ponencia para el Congreso Internacional de Americanistas de 1910, interpretó la escena de las cuatro direcciones en el Codex Porfirio Díaz como una representación figurativa de las correcciones del periodo de Venus. De paso identificó a la montaña partida como «Tepexic [...] u Ometepetl, [...] o más bien, el Tonacatepetl, dividido por Nanauatl. » (Beyer 1965, p. 295). En mixteco el nombre de Tepeji es simplemente Cavua, «Peña ». Según habitantes de Chigmecatitlan, uno de los pueblos mixtecos más al Norte, el nombre mixteco de Huehuetlan es Tey chee, "Hombre grande ", y el del Tentzon: Yucu Chee, "Monte grande". Según la Relación Geográfica de Huehuetlan, la quebrada donde está metido el pueblo se llama Tetlilucan, "lugar donde se ennegrecen las piedras » (Relaciones geográficas 1984-1985, II, p. 211).

8. Lo mismo sugieren el Lienzo de Tlapiltepec y el Rollo Selden, que asocian imágenes del Chicomoztoc con la dirección del Noroeste. Vindobonensis, p. 39, localiza el Chicomoztoc inmediatamente después de los grandes volcanes, es decir al Norte de la Mixteca. También las versiones nauas generalmente sitúan Chicomoztoc en el Norte (más al Norte aún, entonces). En algunas de esas versiones Mixtecatl, el ancestro de los mixtecos, vino de Chicomoztoc. Los mismos códices mixtecos, sin embargo, enfocan el Arbol de Apoala como origen de las dinastías, pero el concepto de la « Cueva Siete » ha sido documentado entre los mixtecos de Nuyoo (Monaghan 1995, p. 210).

9. Se trata obviamente de la Abuela que hasta hoy es la Patrona del temazcal en la Mixteca. Compárese la escena de Nuttall, p. 15, donde la protagonista pide un hijo a esta Diosa. Burgoa (1934, I, p. 289) confirma que el Poniente es la dirección buena " para la generación y multiplicación de los hombres ».

10. Burgoa (1934, I, pp. 337-341) describe este sepulcro con detalle : se encontraba en el Cerro de los Cervatillos. En el Codex Selden, p. 7-IV, vemos este Templo de la Muerte en asociación con el Cerro de los Cervatillos y el Lugar de la Muerte (Ñuundaya, Chalcatongo).

11. Compárense las escenas del origen de los fundadores de las dinastías en los códices mixtecos (Nuttall, pp. 1 y 19a ; Bodley, pp. 2-IV, 40-I, 38-I, Selden, p. 1), así como el signo para nacimiento en la escritura jeroglífica maya (" upended frog ").

12. Una representación pictórica de este Corazón del Pueblo Mixteco dentro de una cueva se ve en el Codex Selden, p. 6-II. Textos nauas documentan el concepto del Corazón de la Comunidad ( Altepetl iyollo) como nombre del Envoltorio Sagrado que representa al Fundador y Dios Patrón del pueblo (Anders \& Jansen 1994, pp. 71-72). Para un análisis de estos "corazones" y de su relación con « los cerros de establecimiento ", véase López Austin 1994, pp. 169 sqq.

13. En el Lienzo de Tequixtepec la serie de los cuatro signos direccionales, representados de manera linear, es precedida por el signo Monte con Recinto de Sangre. De allí vinieron los fundadores de la dinastía para establecerse en su primer asentamiento entre los volcanes. Podemos interpretar ese lugar como el " altepetl de sangre ", es decir como una representación de la comunidad en su aspecto de lugar de origen primordial.

14. El cosmograma de la primera página del Codex Fejérváry-Mayer muestra las mismas asociaciones en forma de ejes. Véase el comentario de Anders, Jansen \& Pérez Jiménez 1994.

15. Hay que precisar que el sol en el signo de Teotlillan solamente corresponde a la palabra teotl, «Dios ». La parte principal del topónimo es el Tlillan, el Templo Oscuro de Ciuacoatl, que no se asocia con el Oriente, sino más bien con el Sur. En cuanto a Mitlatongo, efectivamente es un Lugar de la Muerte (Dzandaya), pero siempre que lo podemos identificar en los códices mixtecos, su representación se distingue del signo del Sur. En un caso (Selden, p. 14) se agrega al Templo de la Muerte (Andaya) un ave (dzaa) como complemento fonético para garantizar la lectura Dzandaya. En otro (Bodley, p. 3-IV) se pinta como un Cerro de la Calavera.

16. Este procedimiento de rebautizar el códice es prematuro y puede confundir al lector. De la misma manera Brotherston se refiere al Vindobonensis como " Anales de Tepexic ", porque piensa que el signo del Monte Partido ocupa un lugar céntrico en ese documento. En mi opinión es más probable que el Vindobonensis procede de Tilantongo, ya que este lugar es el primero en ser mencionado en la primera página (p. 52) y fue la primera comunidad a la que llegó el protagonista divino, el Señor 9 Viento Quetzalcoatl (p. 48).

17. Es iluminador el ensayo de Bartolomé (1997, cap. 6) sobre las personas físicas, sociales y espirituales en las culturas indígenas de México.

18. En Vaticano $B$, p. 71, este esquema gráfico es reducido a cuatro signos calendáricos alrededor de las fauces del lagarto. 
19. Según Sahagún (Libro VI, cap. 29) las mujeres muertas en el parto fueron identificadas explícitamente con Ciuacoatl ( $c f$. Klein 1988 y Barba de Piña Chan 1993). Esta compleja diosa a su vez tiene lazo con Tlazolteotl, cuya identidad ha sido tema de muchos estudios (por ejemplo Sullivan 1982 y DurandForest 1988). En Borgia las faldas de las mujeres contienen huesos, en mex. 20 calaveras y corazones. Estos elementos son atributos de la Diosa de la Muerte, pero también representan la plegaria (Durán 1967, I, p. 280). Yollotlicue, " ella con la falda de corazones ", aparece también como un aspecto de Itzpapalotl, la deificada punta de la flecha (Borgia, p. 66 ; $c f$. la Señora 9 Caña en Borgia, p. 47, y Nuttall, p. 51).

20. Sobre estas deidades véase Mönnich (1973). Los porta-estandartes asociados con el Templo Mayor en el famoso dibujo de Sahagún (Codex Matritense) llevan los nombres calendáricos de 5 Lagartija y 5 Casa. El día 5 Lagartija aparece asociado con un templo en el Codex Magliabechi, p. 87.

21. Compárese con la representación de Huehuecoyotl en el Codex Nuttall, p. 78. Las manos pintadas pueden ser referencias al sacrificio humano (Sahagún, Libro II, cap. 34) o a una plegaria (Durán 1967, I, p. 280). También existe la impresión de un pie como motivo iconográfico, por ejemplo en la cara de la Diosa 9 Caña (Borgia, p. 47).

22. Sobre este valor mántico de los animales, véase Anders \& Jansen 1993, pp. 125 sqq. Sobre el carácter simbólico del calendario en general, véanse Tedlock 1982, Loo 1987 y Doesburg \& Carrera González 1996.

23. Uno de los términos mixtecos para "batalla" es tatnu yusa, "lanza, escudo". Un "valiente señalado " se llama tay ninihi tatnu ninihi yusa, "hombre que recibió la lanza, que recibió el escudo" (Alvarado).

24. Esto hace pensar en el histórico y simbólico viaje de Topiltzin Quetzalcoatl con el Señor 8 Venado a la Casa del Sol (Jansen 1997a, 1997c).

25. Véase el comentario de Anders, Jansen y Reyes García (1993), también para la explicación del concepto del tonalpoalli organizado en "columnas" de cinco días (como se ve, por ejemplo, en Borgia, pp. 1-8).

26. Las conclusiones de McAnany (1995) acerca de la importancia del culto a los ancestros entre los mayas valen para toda Mesoamérica. Compárese el profundo estudio de López Austin (1994) sobre los conceptos de la religión mesoamericana y el ensayo de Quezada (1996) sobre la dualidad genérica.

27. Tal práctica mántica está bien documentada en Mesoamérica, por ejemplo entre los mixtecos (Anders, Jansen \& Pérez Jiménez 1994), los mazatecos (Boege 1988) y los quichés (Tedlock 1982). Para la idea de la "mesa " véase también Loo 1987, pp. 191 sqq.

28. El naualtocaitl es explicado por Ruiz de Alarcón mismo como «nombre metafórico [...] que usan los hechiceros » (Tratado III, cap. 2).

29. Modificamos la traducción que el mismo Ruiz de Alarcón hizo de los textos en nauatl, ya que su interpretación a menudo resulta deficiente, por ser el resultado de una inadecuada comprensión y comunicación intercultural. En este caso traduce los cuatro nombres como " dioses de amor, v.g. cupido, venus,... ». Las cuatro manifestaciones de Tlazolteotl-Ixcuina son mencionadas también por Sahagún (Libro I, cap. 12) y se ven representadas en el Codex Laud, pp. $39-42$ ( $c f$. Anders \& Jansen 1994, pp. 187 sqq.).

30. Los quiché designan al sacerdote chamánico como chuchkajaw y a los Ancestros como Nantat (Tedlock 1982) - ambos términos son traducidos como " madre-padre». En la vida política-ceremonial azteca encontramos a los máximos funcionarios tlatoani y ciuacoatl, que simbólicamente corresponden a Tezcatlipoca-Huitzilopochtli y Tlazolteotl-Ciuacoatl (cf. Quezada 1996).

31. Véanse López Austin 1994 y Jansen 1997c. Es interesante notar que en nauatl existe la expresión momamali in teuatl in tlachinolli, "se taladra (como fuego) el divino conflicto (" agua y fuego ") ", para referir al principio de una guerra (Sahagún, Libro VI, cap. 10).

32. Las referencias a los grandes mitos tienen sus implicaciones en el nivel psicológico (véanse las interpretaciones de Jung y en particular el estudio de Nortwick, 1996) y, por eso, generan y canalizan fuerzas espirituales. Donde los rituales y la historia sagrada expresan las experiencias y visiones colectivas, remiten a la identidad étnica como fuente de "poder». Es fructífero e importante explorar este aspecto en la interpretación de los códices. En la vasta literatura sobre el tema destacan los estudios de Miguel Bartolomé y Alicia Barabas por su profundidad y realismo - para nuestro análisis tienen especial relevancia los capítulos 3 y 4 de Bartolomé 1997.

33. Véase por ejemplo Reichard 1977, láminas XII-XIX, XXII Y XXIV. Al igual que las parejas del mex. 20 muchos protagonistas de las pinturas de arena llevan flechas en las manos. Encontramos hasta una profunda coincidencia entre la figura de Mujer Cambiante (Changing Woman) y el complejo de Ciuacoatl.

34. Cf. Jansen \& Pérez Jiménez 1998. De paso notamos que la visita anterior de la princesa 6 Mono al Vehe Kihin (Selden, p. 6) tuvo lugar el día 6 Serpiente, que es el día que sigue 5 Lagartija (tan importante en mex. 20) y que a la vez tenía una gran importancia ritual para el Señor 8 Venado, que acompañaba a la 
princesa 6 Mono en aquella ocasión : 6 Serpiente cae dos días antes de 8 Venado, como « vísperas de sus cumpleaños ".

35. Por eso la sabia mazateca María Sabina condenaba el uso frívolo de los hongos alucinógenos por los hippies como un « juego " sin respeto, algo indebido y escandaloso, cuyo resultado fue que los niños santos perdieron su pureza y su fuerza (Estrada 1977, pp. 112-123).

\section{BIBLIOGRAFÍA}

Alvarado, Francisco de, 1962 [1593]. - Vocabulario en Lengua Mixteca, Instituto Nacional de Antropología e Historia-Instituto Nacional Indigenista, México.

ANDERS, Ferdinand \& Maarten JANSEN, 1988. - Schrift und Buch im alten Mexiko, Akademische Druck-u. Verlagsanstalt, Graz.

—, 1993. - El manual del adivino. Libro explicativo del llamado Códice Vaticano B, Fondo de Cultura Económica, México.

Anders, Ferdinand, Maarten Jansen \& G. Aurora Pérez Jiménez, 1992a. - Origen e historia de los reyes mixtecos. Libro explicativo del llamado Códice Vindobonensis, Fondo de Cultura Económica, México.

—, 1992b. - Crónica mixteca. El rey 8 Venado, Garra de Jaguar, y la dinastía de TeozacualcoZaachila. Libro explicativo del llamado Códice Zouche-Nuttall, Fondo de Cultura Económica, México.

—, 1994. - El Libro de Tezcatlipoca, Señor del Tiempo. Libro explicativo del llamado Códice Fejérváry-Mayer, Fondo de Cultura Económica, México.

Anders, Ferdinand, Maarten JANSEN \& Luis Reyes García, 1993. - Los templos del cielo y de la oscuridad. Oráculos y liturgia. Libro explicativo del llamado Códice Borgia, Fondo de Cultura Económica, México.

ANDERS, Ferdinand, Maarten JANSEN, con una contribución de Alejandra CruZ OrTIZ, 1994 . Pintura de la muerte y de los destinos. Libro explicativo del llamado Códice Laud, Fondo de Cultura Económica, México.

ANDERS, Ferdinand \& Maarten JANSEN, con contribuciones de Jessica Davilar y Anuschka VAN'T Hooft, 1996. Libro de la vida. Texto explicativo del llamado Códice Magliabechiano, Fondo de Cultura Económica, México.

BADE, Bonnie, 1994. - «Contemporary Mixtec Medicine. Emotional and Spiritual Approaches to Healing ", in : G. Johnson \& D. Sharon (eds.), Cloth and Curing. Continuity and Change in Oaxaca, pp. 61-69, San Diego Museum Papers, 32, San Diego.

BaRBa DE PIÑA ChAN, Beatriz, 1993. - «Las Cihuapipiltin : sublimación de la muerte por parto ", in: B. Dahlgren de Jordán (ed.), III Coloquio de Historia de la Religión en Mesoamérica y áreas afines, pp. 175-185, Universidad Nacional Autónoma de México, México.

Bartolomé, Miguel A., 1997. - Gente de Costumbre y Gente de Razón. Las identidades étnicas en México, Instituto Nacional Indigenista-Siglo xxI, México.

BEYER, Hermann, 1965. - «Correcciones del periodo de Venus en los códices Borgia y Porfirio Díaz ", El México Antiguo, x, pp. 291-295, Sociedad Alemana Mexicanista, México.

BibliothèQue nationale, 1976. - Aztlán, terre des Aztèques. Images d'un Nouveau Monde, Bibliothèque nationale, Paris. 
Boban, Eugène, 1891. - Documents pour servir à l'histoire du Mexique. Catalogue raisonné de la collection de M. E.-Eugène Goupil (ancienne collection J.-M.-A. Aubin). Manuscrits figuratifs et autres [...], 2 vol. + atlas, Ernest Leroux, Paris.

BOEGE, Eckart, 1988. - Los mazatecos ante la nación. Contradicciones de la identidad étnica en el México actual, Siglo xxI, México.

Boturini Benaduci, Lorenzo, 1974 [1746]. - Idea de una Nueva Historia General de la América Septentrional, Porrúa, México.

Brotherston, Gordon, 1995. - Painted Books from México, British Museum Press, London.

BurgoA, fray Francisco de, 1934. - Geográfica Descripción (I, II), Publicaciones del Archivo General de la Nación, 25, 26, México.

Byland, Bruce E. \& John M. D. Pohl, 1994. - In the Realm of 8 Deer, University of Oklahoma Press, Norman.

CAso, Alfonso, 1949. — «El Mapa de Teozacoalco », Cuadernos Americanos, viII, 5, pp. 145181.

—, 1961. — «Los lienzos mixtecos de Ihuitlan y Antonio de León ", in : Homenaje a Pablo Martínez del Río, pp. 237-274, México.

—, 1964. - Interpretación del Códice Selden 3135, Sociedad Mexicana de Antropología, México.

—, 1966. - «El culto al sol. Notas a la interpretación de W. Lehmann. ", Traducciones mesoamericanistas, tomo I, pp. 177-190, Sociedad Mexicana de Antropología, México.

Doesburg, G. Bas, van, 1996. - La herencia del Señor Tico. Fundación y desintegración de un cacicazgo cuicateco, disertación doctoral, Universidad de Leiden, Leiden.

Doesburg, G. Bas, van \& Florencio Carrera González, 1996. - Códice Ixtlilxóchitl. Apuntaciones y pinturas de un historiador, Fondo de Cultura Económica, México.

Doesburg, G. Bas, van \& Olivier van BuREn, 1997. - « The prehispanic history of the Valley of Coixtlahuaca, Oaxaca ", in : M. Jansen \& L. Reyes García (eds.), Códices, Caciques y Comunidades, Cuadernos de la Historia Latinoamericana, 5, pp. 103-160, Asociación de Historiadores Latinoamericanistas Europeos.

Durán, fray Diego, 1967. - Historia de las Indias de Nueva España e islas de Tierra Firme, A. Ma. Garibay (ed.), 2 vol., Porrúa, México.

Durand-Forest, Jacqueline de, 1988. — « Tlazolteotl », in : J. K. Josserand \& K. Dakin (eds.), Smoke and Mist. Mesoamerican Studies in Memory of Thelma D. Sullivan, I, pp. 191-215, British Archaeological Reports International Series 402, Oxford.

Estrada, Alvaro, 1977. - Vida de María Sabina, la sabia de los hongos, Siglo xxi, México.

Freidel, David \& Linda Schele \& Joy Parker, 1993. - Maya Cosmos. Three Thousand Years on the Shaman's Path, Morrow, New York.

Furst, Peter T., 1980. - Alucinógenos y cultura, Fondo de Cultura Económica, México.

GARZA, Mercedes de la, 1990. - Sueño y alucinación en el mundo náhuatl y maya, Universidad Nacional Autónoma de México, México.

Glass, John B., 1964. - Catálogo de la colección de códices, Museo Nacional de Antropología, Instituto Nacional de Antropología e Historia, México.

—, 1975. - «A Survey of Native Middle American Pictorial Manuscripts ", in : H. F. Cline (ed.), Handbook of Middle American Indians, vol. 14 : Guide to Ethnohistorical Sources, part 3, pp. 3-80, University of Texas Press, Austin. 
Glass, John B. \& Donald Robertson, 1975. - «A Census of Native Middle American Pictorial Manuscripts ", in: H. F. Cline (ed.), Handbook of Middle American Indians, vol. 14 : Guide to Ethnohistorical Sources, part 3, pp. 81-252, University of Texas Press, Austin.

JANSEN, Maarten, 1982. - Huisi Tacu, estudio interpretativo de un libro mixteco antiguo. Codex Vindobonensis Mexicanus I, Centro de estudios y documentación latino-americanos, Amsterdam.

—, 1994. - La Gran Familia de los reyes mixtecos. Libro explicativo de los llamados Códices Egerton y Becker II, Fondo de Cultura Económica, México.

—, 1997a. — «Un viaje a la Casa del Sol », Arqueologia Mexicana, vol. Iv, 23, pp. 44-49.

—, 1997b. — «Símbolos de poder en el México antiguo ", Anales del Museo de América, 5, pp. 73-102.

—, 1997c. — « La Serpiente Emplumada y el amanecer de la historia », in : M. Jansen \& L. Reyes García (eds.), Códices, caciques y comunidades, pp. 11-63, Asociación de Historiadores Latinoamericanistas Europeos.

JANSEN, Maarten \& Gabina Aurora PÉREZ JiMÉNEZ, 1998. — « Dos princesas mixtecas en Monte Albán ", Arqueología Mexicana, vol. v, 29, pp. 28-33.

KLEIN, Cecilia F., 1988. — « Rethinking Cihuacoatl. Aztec political imagery of the conquered woman ", in : J. K. Josserand \& K. Dakin, (eds.), Smoke and Mist. Mesoamerican Studies in Memory of Thelma D. Sullivan, I, pp. 237-277, British Archaeological Reports International Series 402, Oxford.

LehmanN, Walter, 1905. - «Die 5 im Kindbett gestorbenen Frauen des Westens und die 5 Götter des Südens in der mexikanischen Mythologie ", Zeitschrift für Ethnologie, 37, pp. 848-871.

—, 1905. — « Les peintures mixteco-zapotèques et quelques documents apparentés ", Journal de la Société des Américanistes, nouvelle série, 2 (2), pp. 241-280.

_, 1966. - « Las cinco mujeres del oeste muertas en el parto y los cinco dioses del sur en la mitología mexicana ", Traducciones mesoamericanistas, tomo I, pp. 147-175, Sociedad Mexicana de Antropología, México [traducción española del artículo de 1905 por B. Dahlgren de Jordán].

León Portilla, Miguel, 1996. - Códice Alfonso Caso. La vida de 8-Venado, Garra de Tigre (Colombino - Becker I), Patronato Indígena, México.

Loo, Peter L. van Der, 1987. - Códices, Costumbres y Continuidad, disertación doctoral, Universidad de Leiden, Leiden.

López Austin, Alfredo, 1994. - Tamoanchan y Tlalocan, Fondo de Cultura Económica, México.

McAnany, Patricia A., 1995. - Living with the Ancestors. Kinship and Kingship in Ancient Maya Society, University of Texas Press, Austin.

MöNNICH, Anneliese, 1973. — « Las deidades mexicanas llamadas Tonaleque, "Señores de los signos de los días " ", Indiana, I, pp. 65-72.

Monaghan, John, 1995. - The Covenants with Earth and Rain. Exchange, sacrifica and revelation in Mixtec sociality, University of Oklahoma Press, Norman \& London.

NoR TwICK, Thomas, van, 1996. - Somewhere I have never travelled. The Hero's Journey, Oxford University Press, New York-Oxford.

Nowotny, Karl Anton, 1959. - « Die Bilderfolge des Codex Vindobonensis und verwandter Handschriften ", Archiv für Völkerkunde, III, pp. 156-200. 
—, 1961. — Tlacuilolli, die mexikanischen Bilderhandschriften, Stil und Inhalt, mit einem Katalog der Codex Borgia Gruppe, Monumenta Americana, Gebr. Mann, Berlin.

Parmenter, Ross, 1982. - Four Lienzos of the Coixtlahuaca Valley, Dumbarton Oaks, Washington, DC.

Pohl, John M. D. \& Bruce E. Byland, 1990. — « Mixtec landscape perception and archaeological settlement patterns ", Ancient Mesoamerica, 1(1), pp. 113-131.

Quezada, Noemí, 1996. - " Mito y género en la sociedad mexica ", Estudios de Cultura Náhuatl, 26, pp. 21-40.

QuiÑones Keber, Eloise, 1995. - Codex Telleriano-Remensis. Ritual, Divination and History in a Pictorial Aztec Manuscript, University of Texas Press, Austin.

ReIChard, Gladys A., 1974. - Navaho religion. A study of symbolism, Bollingen Series, Princeton University Press, Princeton.

—, 1977. - Navajo Medicine Man Sandpaintings, Dover Publications, New York.

Relaciones geográficas del siglo XVI, 1984, tomos 2-3: Antequera, R. Acuña (ed.), Instituto de Investigaciones Antropológicas, Universidad Nacional Autónoma de México, México.

—, 1984-1985, tomos 4-5 : Tlaxcala, R. Acuña (ed.), Instituto de Investigaciones Antropológicas, Universidad Nacional Autónoma de México, México.

Reyes, Antonio de los, 1976 [1593]. - Arte en Lengua Mixteca, Vanderbilt University Publications in Anthropology, 14, Nashville.

Ruiz de Alarcón, Hernando y otros, 1953 [1629]. — Tratado de las idolatrías, supersticiones, dioses, ritos, hechicerías y otras costumbres gentílicas de las razas aborígenes de México, Ediciones Fuente Cultural, México.

SAHagún, Bernardino de, 1975. - Historia General de las cosas de Nueva España, A. Ma. Garibay (ed.), Porrúa, México.

—, 1979. - Códice Florentino [edición facsimilar], México.

Schultze JenA, Leonhard, 1933-1938. - Indiana, 3 tomos, Gustav Fischer, Jena.

SELER, Eduard, 1887. - « Der Codex Borgia und die verwandten aztekischen Bilderschriften », Zeitschrift für Ethnologie, XIX, pp. 105-114 [reproducido en Gesammelte Abhandlungen, I, pp. 133-144].

-, 1902. - Codex Vaticanus Nr. 3773. Eine altmexikanische Bilderschrift der Vatikanischen Bibliothek, 2 tomos, 1902, Berlin.

—, 1904-1909. - Codex Borgia. Eine altmexikanische Bilderschrift der Bibliothek der Congregatio de Propaganda Fide, 3 tomos, Berlin.

—, 1902-1923. - Gesammelte Abhandlungen zur Amerikanishen Sprach- und Altertumskunde (I-v), Berlin [Reimpresión 1960-1961, Akademische Druck-u. Verlagsanstalt, Graz].

—, 1963. - Comentarios al Códice Borgia (traducción española de Seler 1904-1909), Fondo de Cultura Económica, México [Reimpresión 1988].

Serna, Jacinto de la, 1953. - Véase : Ruiz de Alarcón y otros, 1953, tomo II.

Simonin, Martine, 1998. - Manuscrit Aubin $n^{\circ}$ 20, Presses Universitaires du Septentrion, Villeneuve d'Ascq.

Smith, Mary Elizabeth, 1973. - « The Relationship between Mixtec manuscript painting and the Mixtec language ", in : E. P. Benson (ed.), Meso-american Writing Systems, pp. 47-98, Dumbarton Oaks, Washington, DC.

Sullivan, Thelma, 1982. - "Tlazolteotl-Ixcuina. The great Spinner and Weaver ", in: E. P. Benson \& E. Hill Boone (eds.), The Art and Iconography of Late Post-Classic México, pp. 7-35, Dumbarton Oaks, Washington, DC. 
Tedlock, Barbara, 1982. - Time and the Highland Maya, University of New Mexico Press, Albuquerque.

YonedA, Keiko, 1981. - Los mapas de Cuauhtinchan y la historia cartográfica prehispánica, Archivo General de la Nación, México. 